Central Washington University

ScholarWorks@CWU

All Master's Theses

Master's Theses

Summer 2016

\title{
Sustainable Safari Practices: Proximity to Wildlife, Educational Intervention and the Quality of Experience
}

Ryan Devine Tarver

Central Washington University, tarverr@cwu.edu

Follow this and additional works at: https://digitalcommons.cwu.edu/etd

Part of the African Studies Commons, Environmental Studies Commons, Nature and Society Relations Commons, Place and Environment Commons, Recreation, Parks and Tourism Administration Commons, and the Tourism Commons

\section{Recommended Citation}

Tarver, Ryan Devine, "Sustainable Safari Practices: Proximity to Wildlife, Educational Intervention and the Quality of Experience" (2016). All Master's Theses. 483.

https://digitalcommons.cwu.edu/etd/483

This Thesis is brought to you for free and open access by the Master's Theses at ScholarWorks@CWU. It has been accepted for inclusion in All Master's Theses by an authorized administrator of ScholarWorks@CWU. For more information, please contact scholarworks@cwu.edu. 
SUSTAINABLE SAFARI PRACTICES: PROXIMITY TO WILDLIFE,

EDUCATIONAL INTERVENTION AND

THE QUALITY OF EXPERIENCE

\begin{abstract}
A Thesis
Presented to

The Graduate Faculty

Central Washington University

In Partial Fulfillment

of the Requirements for the Degree

Master of Science

Cultural and Environmental Resource Management
\end{abstract}

by

Ryan Devine Tarver

July 2016 


\section{CENTRAL WASHINGTON UNIVERSITY}

Graduate Studies

We hereby approve the thesis of

Ryan Devine Tarver

Candidate for the degree of Master of Science

APPROVED FOR THE GRADUATE FACULTY

Dr. Dominic Klyve, Committee Chair

Dr. Kenneth Cohen

Dr. Robert Perkins

Dean of Graduate Studies 


\author{
ABSTRACT \\ SUSTAINABLE SAFARI PRACTICES: PROXIMITY TO WILDLIFE, \\ EDUCATIONAL INTERVENTION AND
}

THE QUALITY OF EXPERIENCE

by

Ryan Devine Tarver

July 2016

This research examines the perceived quality of experience for safari tourists in relation to wildlife viewing proximities and the potential of educational interventions as a management strategy to mitigate adverse impacts of safari participant crowding. Crowding emanates from the safari tourist preferences to obtain close proximity to animals, particularly large mammals. Recognizing these preferences and associated impacts to animal behavior defined in previous research, we develop and deliver a survey instrument designed to measure the perceived quality of experience of the safari tourist while controlling for the viewing proximity variable. The survey instrument involves responding to stock photos selected to represent the safari-tour experience, using a Likert type rating scale. Using a "pre-treatment" and "post treatment" protocol, we share an educational management intervention that correlates the impact of intervention on safari participants' perceptions of the quality of safari experience based on proximity to animals. 


\section{ACKNOWLEDGMENTS}

First off, I would like to extend my gratitude to the School of Graduate Studies and Central Washington University for making this experience possible. I would also like to thank my thesis committee for their continual support and ability to work as a team throughout the thesis process. A special thanks to Dr. Cohen for reaching out to me with this opportunity and seeing my potential to succeed in the academic realm. Last, but not least, I would like to thank my friends and family for being there for me as I faced the challenges of graduate school, with a special thanks to my amazing parents for trusting and encouraging me to find my path. 


\section{TABLE OF CONTENTS}

Chapter

1 INTRODUCTION. 1

2 LITERATURE REVIEW 4

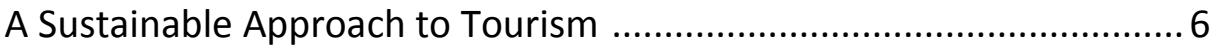

The Wildlife Tourism Experience ...................................................... 8

Ngorongoro Conservation Area: A Case Study .................................. 9

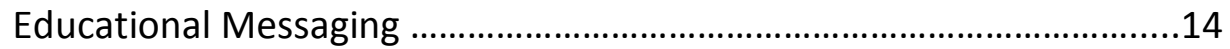

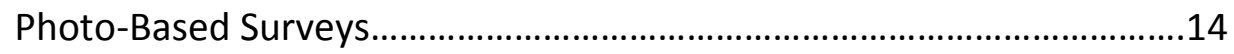

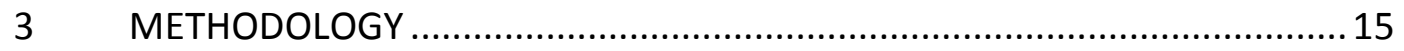

Survey Content \& Design .......................................................... 15

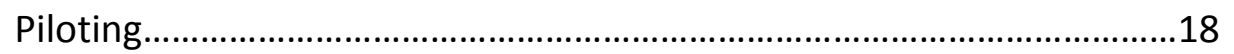

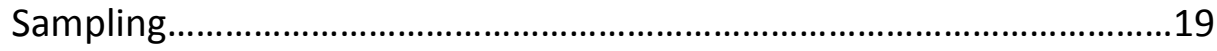

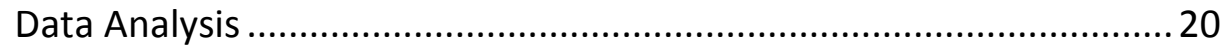

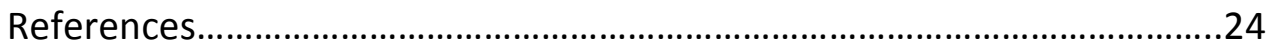

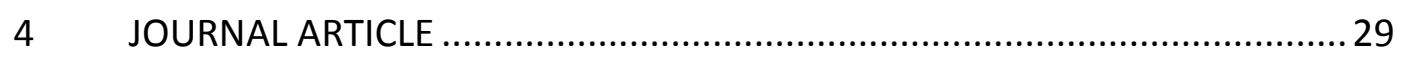

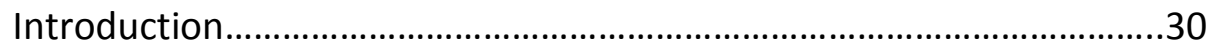

Ngrorongoro Conservation Area: A Case Study ............................... 33

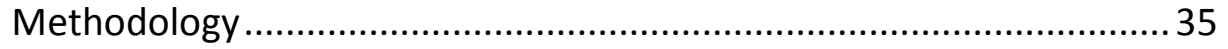

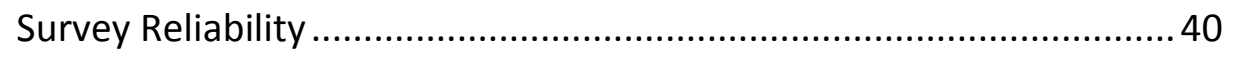

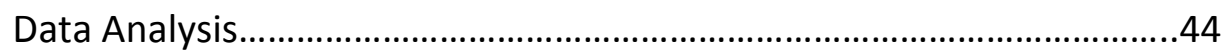

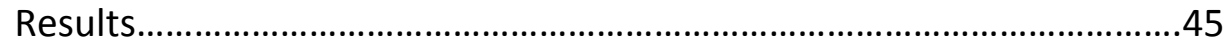

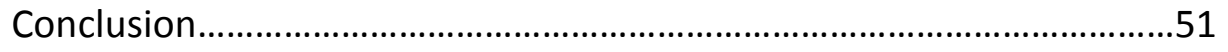

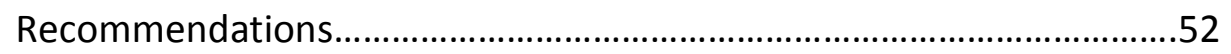

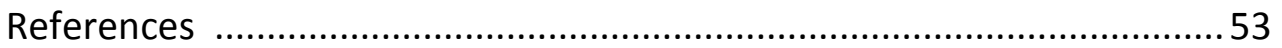




\section{LIST OF TABLES}

Table

Page

1 Survey Internal Consistency Scores (Cronbach's Alpha) ....

2 Internal Reliability across Proximity Groups (Cronbach's Alpha)

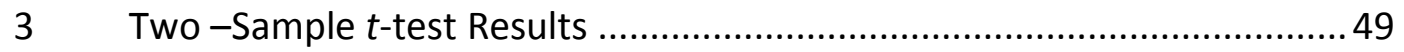

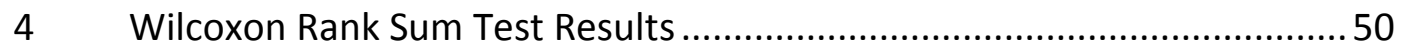




\section{LIST OF FIGURES}

$\begin{array}{ll}\text { Figure } & \text { Page }\end{array}$

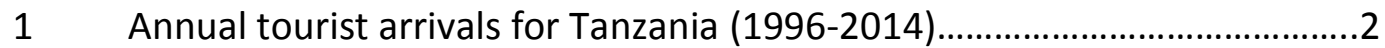

$2 \quad$ Location of Ngorongoro Conservation Area .......................................... 11

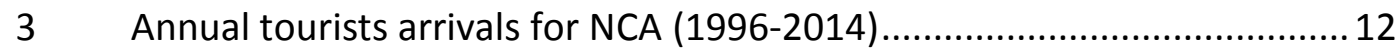

$4 \quad$ Example of photo survey guide and rating scale .......................................17

$5 \quad$ Example of educational intervention page.................................................18

$6 \quad$ Single participant mean score example.................................................. 23

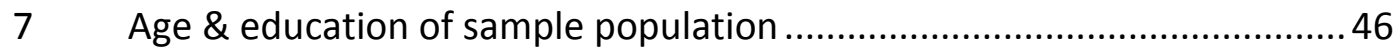




\section{CHAPTER 1}

\section{INTRODUCTION}

This research examines the impact of an educational intervention on safari goer's perceptions of the quality of their experience as it relates to their perceived physical proximity to lions in the Ngorongoro Crater. Within the broader sustainable tourism context, the implications of this relationship are extensive. Sustainable tourism is an approach to tourism "that takes full account of its current and future economic, social and environmental impacts, addressing the needs of visitors, the industry, the environment and host communities" (UNWTO, 2006). Economically, tourism is considered to be a reliable industry (Hawkins et al., 2012), thus many developing countries utilize tourism as a vehicle for economic growth (Panitchpakdi, 2012). Notably, Tanzania generates $11.8 \%$ of its GDP through tourism activity, ranking as the countries' single largest industry (Cunningham et al., 2015). Tanzania experienced a record number of international arrivals $(1,113,000)$ in 2014 (WTTC, 2015) (Figure 1). The tourism sector directly employs over 450,000 native Tanzanians and indirectly generates about 1.2 million jobs (Cunningham et al., 2015). Wildlife tourism, specifically safari-related tourism, is the predominant form of tourism in Tanzania (WTTC, 2015). As an economic engine, safaris have the capacity to provide a steady source of revenue as long as the safari experience predictably satisfies safari tourism customers (Gössling et al., 2009).

In the context of sub-Sahara wildlife viewing, the "big five" are the centerpiece of the nature-based tourism experience (Di Minin et al., 2013). Namely, the five species include the African lion (Panthera leo), leopard (Panthera pardus), elephant (Loxodonta 
africana), buffalo (Syncerus caffer), and black rhino (Diceros bicornis) (Williams et al., 2000). A contributing factor to the quality of experience for tourists is the distance at which they are able to view species of interest (Moscardo, 2009; Semenuik et al., 2009). The desire to view flagship species has resulted in higher revenues, greater visitation, more predominant public profiles, and more conservation attention for protected areas that provide habitat for the big five (Higginbottom et al., 2003). For the tourists, wildlife-viewing experiences lead to greater awareness, appreciation and connection to nature, and a heightened sense of personal responsibility when it comes to the state of the environment (Ballantyne et al., 2007; Falk, 2011; Powell et al., 2009).

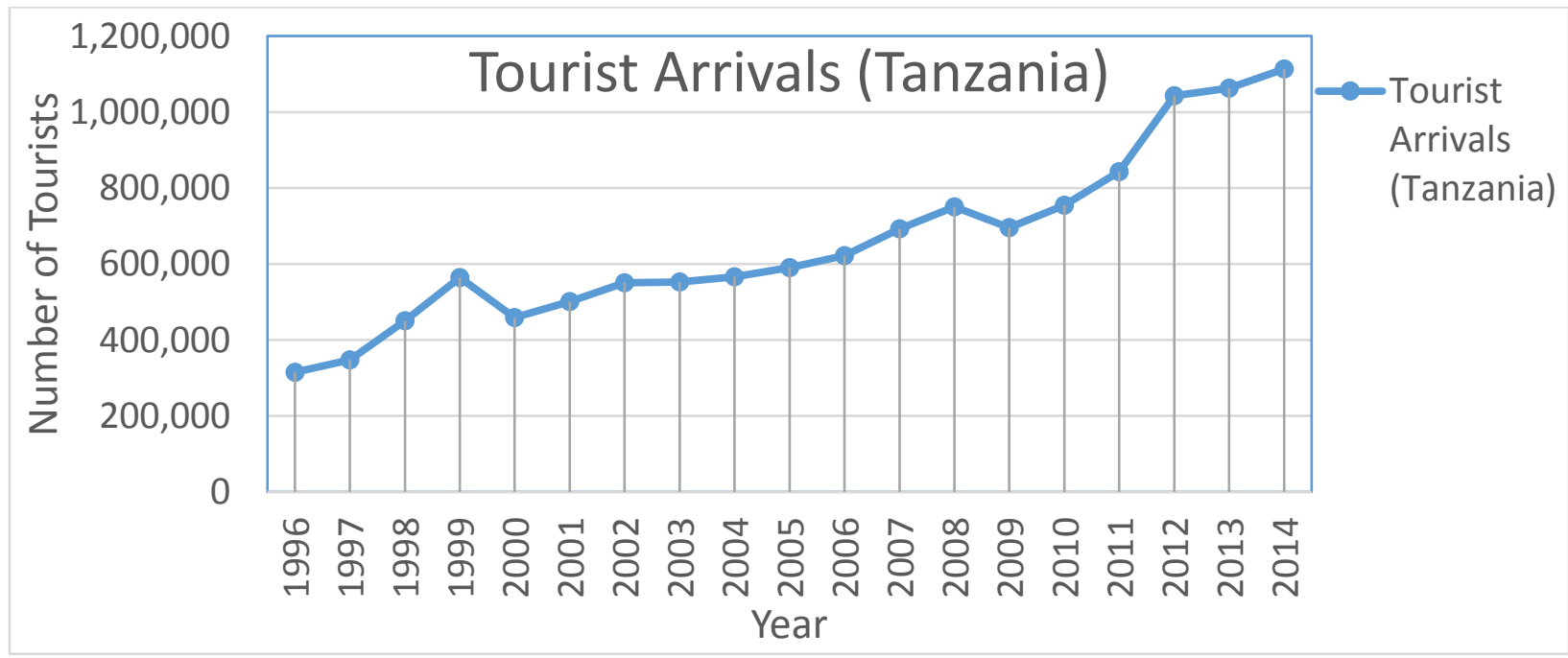

Figure 1. Annual tourist arrivals for Tanzania (1996-2014). (WTTC, 2015)

However, not all outcomes of safari tourism activity are positive. Several studies report that flagship species, like the big five, are more vulnerable to adverse impacts due to the preference to view them, especially at close proximities (Durant et al., 2011; Mosser \& Packer, 2009; Fryxell, et al., 2007; Hopcraft et al., 2005). For example, lions 
have experienced changes in reproductive activity, feeding time, prey-predator relationship, and increased resting time due to artificial shade provided by safari vehicle congestion (Nyahongo et al., 2007).

Wildlife area managers face the challenge of preserving the species responsible for generating tourism revenue, without compromising the quality of experience for the safari customer (Melita \& Mendlinger, 2013). If the quality of experience significantly and persistently deteriorates, it may compromise the safari industry's ability to compete in the international tourism sector. Herein lies the paradox central to this research: if proximity to flagship species (lions) negatively affects behavior and propagation, how can the resource i.e., lions (and the biotic community necessary to sustain their viability) be sustained without negatively affecting the quality of the experience of the safari customer?

To answer this question, this study looked to measure the impact of an educational intervention on tourists' perceived quality of experience in relation to wildlife viewing distance. This case study utilizes survey research methodology with a photo imagery platform to provide NCA management with data that indicates safari goers' preferences in order to substantiate practices that may better preserve the wildlife resource as well as the quality of experience for the safari tourists. 


\section{CHAPTER 2}

\section{LITERATURE REVIEW}

Human globetrotting influences economic, environmental and societal changes on a global scale (CREST, 2014). Tourism is currently one of the world's largest industries that with 1.1 billion international participants in 2014 (WTTC, 2015). Tourism began gaining traction as an industry following the Second World War. The tourism boom coincided with emerging models of development that motivated monetary gains and through large-scale infrastructure projects that maximize visitation capacity of a destination (Mowforth \& Munt, 2009). The capitalistic nature of mass tourism catered to the experience of the tourists and placed little focus on environmental and cultural degradation caused by the industry (Mowforth \& Munt, 2009). However, this creates a paradox-- by visiting a place of interest a tourist may simultaneously be contributing to its destruction. Furthermore, the natural and cultural attractions of a location may face degradation if the number of travelers consistently exceeds the carrying capacity of an area (Butler, 1992).

Globalization and development theories have directly affected the structure of the tourism industry (Mowforth \& Munt, 2009). The modernization paradigm following the Second World War, promoted the belief that a developmental divide existed between "third world" countries and the "western world" (Scheyvens, 2002). The key focus of this paradigm is economic growth, which influences local populations to take part in mass consumerism activities (Rostow, 1960). Developing countries have identified mass tourism as a way of stimulating the economy through job creation and 
large-scale infrastructure projects (Scheyvens, 2002). The byproduct of this approach has resulted in socio-cultural, economic and environmental problems for members of rural communities (Bhatta, 2014).

Mass tourism development requires major infrastructure in the form of highways, airports, communication networks, water reservoirs and energy production facilities (Bhatta, 2014). Developing countries have relied on substantial loans from organizations like the World Bank to fund large-scale development projects (Telfer, 2002). Governments of developing countries compromise decision-making power by accepting financial investment from foreign investors for things such as tourism development (Comaroff, 2001). In many cases, countries become dependent on resources from foreign investors for developmental support (Telfer \& Sharpley, 2008). This scenario is an example of the dependency theory; a select number of developed countries take advantage of foreign resources at the cost of developing countries (Comaroff, 2001). The Dependency paradigm may result in a shift of power from local to foreign investors causing developing countries to rely on external resources for support (Nepal, 1997). International competitors may possess recourse for economic development but in order to obtain long-term success these operators must incorporate the knowledge and values of the local population (Bhatta, 2014).

Neoliberalism is another developmental model that has influenced international tourism. Neoliberalism is an economic model that calls for a reduction of state intervention and promotes foreign investment and privatization of state enterprises (Telfer \& Sharpley, 2008). Neoliberalism has had a growing influence on tourism activity 
in developing countries (Bhatta, 2014). This developmental approach calls for developing countries to operate under an open market, which leads to competition between local and foreign organizations (Bhatta, 2014). Neo-Liberalism favors global competition between private organizations that can result in decreased involvement of the local population in decision-making processes (Telfer \& Sharpley, 2008). Once again, the external organizations often have greater developmental resources making it difficult for small-scale, local organizations to compete (Scheyvens, 2002). All of the development structures that have been discussed to this point fail to address the value of cultural and environmental sustainability, as well as incorporating the rural population in the decision making process for tourism activities (Telfer \& Sharpley, 2008).

\section{A Sustainable Approach to Tourism}

The large-scale approach to tourism development persisted as the predominant form of tourism activity until the late 1970s. Mass tourism was deemed as "unsustainable" through various models, the most predominant being "Butler's Destination Life-Cycle Model" (Butler, 1992). In response to the detrimental impacts of mass tourism, a new form of tourism began to emerge in the 1980s (Pearce, 1992). Instead of staying at luxury resorts in densely populated areas, alternative travelers chose to spend time at small, locally owned hotels, guesthouses and village accommodations (Pearce, 1992; France, 1997). This shift in awareness motivated alternative development approaches that transferred focus from economic progress to environmental and cultural sustainability. 
The increased awareness of global issues resulted in alternative paradigms that focus on multi-dimensional, long-term outcomes (Liburd \& Edwards, 2010). Alternative forms of development began taking on a bottom-up approach that transferred the focus from economic progress to human and environmental concerns (Telfer \& Sharpley, 2008). These approaches not only call for appropriate attention to environmental and human elements, but also the interconnectedness of people, planet and profit (Liburd \& Edwards, 2010). Schumacher (1973) argued that development should not commence with "goods" or products, but rather with people, education, organization and discipline.

The term "alternative" has faced criticism for having an ambiguous definition left open to interpretation by its user (Brohman, 1996). In response to this criticism, the seminal work titled "The Brundland Report" (1987) defines the five principles of sustainability that should guide alternative approaches of development. The five principles of sustainability include: (I) holistic strategies and planning, (ii) preservation of ecological processes, (iii) protection of cultural heritage and biodiversity, (IV) development that allows for productivity to continue with future generations, and $(\mathrm{V})$ to strive for transnational balance of opportunity and fairness (Hall \& Lew, 1998).

This shift in tourist behavior culminated into an alternative form of tourism known as Ecotourism (Butler, 1992). Many developing countries viewed ecotourism as a great form of poverty alleviation that also aimed to preserve the natural environment, and sustain the traditional culture of the local population (Bhatta, 2014). As ecotourism emerged, it did not possess a concrete, universal definition and fell victim to free 
interpretation by various users, thus facing similar challenges to previously discussed development approaches (Butler, 1992). Fortunately, leading ecotourism organizations have established clear objectives since the birth of ecotourism nearly three decades ago. The International Ecotourism Society (2015) defines Ecotourism as, "responsible travel to natural areas that conserves the environment, sustains the well-being of the local people, and involves interpretation and education."

\section{The Wildlife Tourism Experience}

Wildlife tourism experiences provide opportunity to view and engage with species of interest in a natural (National Parks, conservation areas) or captive setting (zoos, wildlife centers, aquariums) (Cousins, 2007). Due to the nature of this study, the following review will focus on wildlife tourism in natural areas. The growing popularity of wildlife viewing as a tourism activity has been driven by greater awareness of and access to such activities (Higginbottom, 2004). As transportation networks continue to develop, the ability to access natural wildlife becomes easier for the tourists (Rodger et al., 2007). Furthermore, the desire to visit wildlife destinations has grown as the public becomes more interested in and aware of environmental issues (Newsome et al., 2004).

The wildlife viewing experience provides tourists with an opportunity to reconnect with nature in a way that influences perspective and behavior of the tourists (Ballantyne et al., 2009). A growing number of studies have cited the impacts of wildlife tourism- both positive and negative- on participants: wildlife, habitat, and local populations of wildlife tourism destinations. For the tourists, the outcomes are mostly 
positive and include greater awareness, appreciation and connection to nature, and a heightened sense of personal responsibility when it comes to the state of the environment (Ballantyne et al., 2007; Falk et al., 2012; Powell et al., 2009).

Wildlife tourism destinations that provide opportunities to view large mammal result in higher revenues, more predominant public profiles, and more conservation attention than destinations that lack large mammals (Higginbottom, et al., 2003). However, not all outcomes of safari tourism activity are positive. Several studies report that flagship species, like the big five, are more vulnerable to adverse impacts due to the preference to view them, especially at close proximities (Durant et al., 2011; Mosser \& Packer, 2009; Fryxell et al., 2007; Hopcraft et al., 2005). This scenario highlights the paradox of tourism with tourist and wildlife area managers experiencing predominantly positive outcomes while the wildlife resource responsible for generating revenue and customer satisfaction is facing continual degradation.

\section{Ngrorongoro Conservation Area: A Case Study}

Ngorongoro Conservation Area (NCA) established the boundaries for this case study. Established in 1959 as a multiple use area, NCA had the goal of hosting an indigenous population as well as protecting native wildlife (Nyahongo et al., 2007). Covering 8,292 square kilometers $\left(\mathrm{KM}^{2}\right)$ of northern Tanzania (Figure 2), NCA is commonly referred to as "Africa's Eden" due to the array of wildlife, people, landscape and historic archeological sites that are found here (Garland, 2008). The abundant wildlife seen at NCA stems from a diverse habitat comprised of grassland plains, 
savanna woodland, forest, mountains, volcanic craters, lakes, rivers, and swamplands (NCA, 2016). NCA is home to the world's largest ungulate herds, consisting of wildebeest, zebras, and gazelles. The predatory animal population includes lions, spotted hyenas, leopards, and cheetahs. NCA also provides habitat for the endangered black rhino, as well as, 400 species of birds (NCA, 2016).

\section{Ngorongoro Crater}

The primary tourist attraction of NCA is the Ngorongoro crater. According to archeological data, Ngorongoro Crater formed about 2.5 million years ago following the collapse of an active volcano (Skinner et al., 2003). The collapse of the volcano resulted in $264 \mathrm{KM}^{2}$ caldera that ranges $16-19 \mathrm{~km}$ across. The densely forested outer rim of the caldera quickly rises about 610 meters above the grasslands of the crater floor (NCA, 2016). This unique topography has created a contained environment favorable for wildlife viewing, especially at close proximities. A significant portion of the wildlife population is migratory, although a sufficient non-migratory wildlife population allows for year-round wildlife viewing opportunities. 


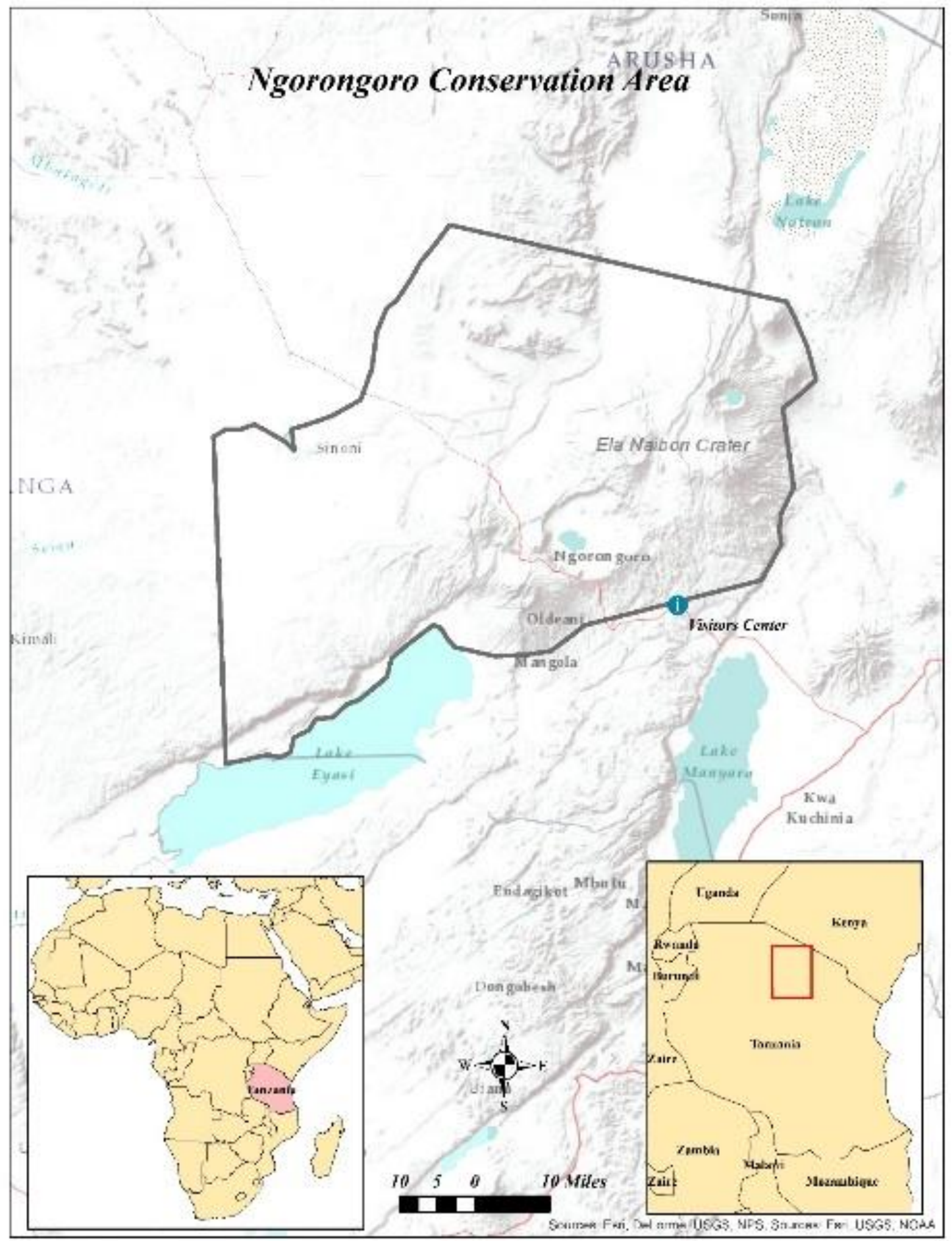

Figure 2. Location of Ngorongoro Conservation Area. 


\section{Vehicle Congestion}

The draw and economic potential of NCA through organized safari tourism does not come without its challenges. As visitation to NCA continues to increase (Figure 3), so does the congestion and exposure of humans to wildlife. The current trend has resulted in overcrowding of tourist vehicles (Nyahongo et al., 2007). The issue of overcrowding can lead to increased environmental degradation and a lower quality of experience for the tourists (Nyahongo et al., 2007).

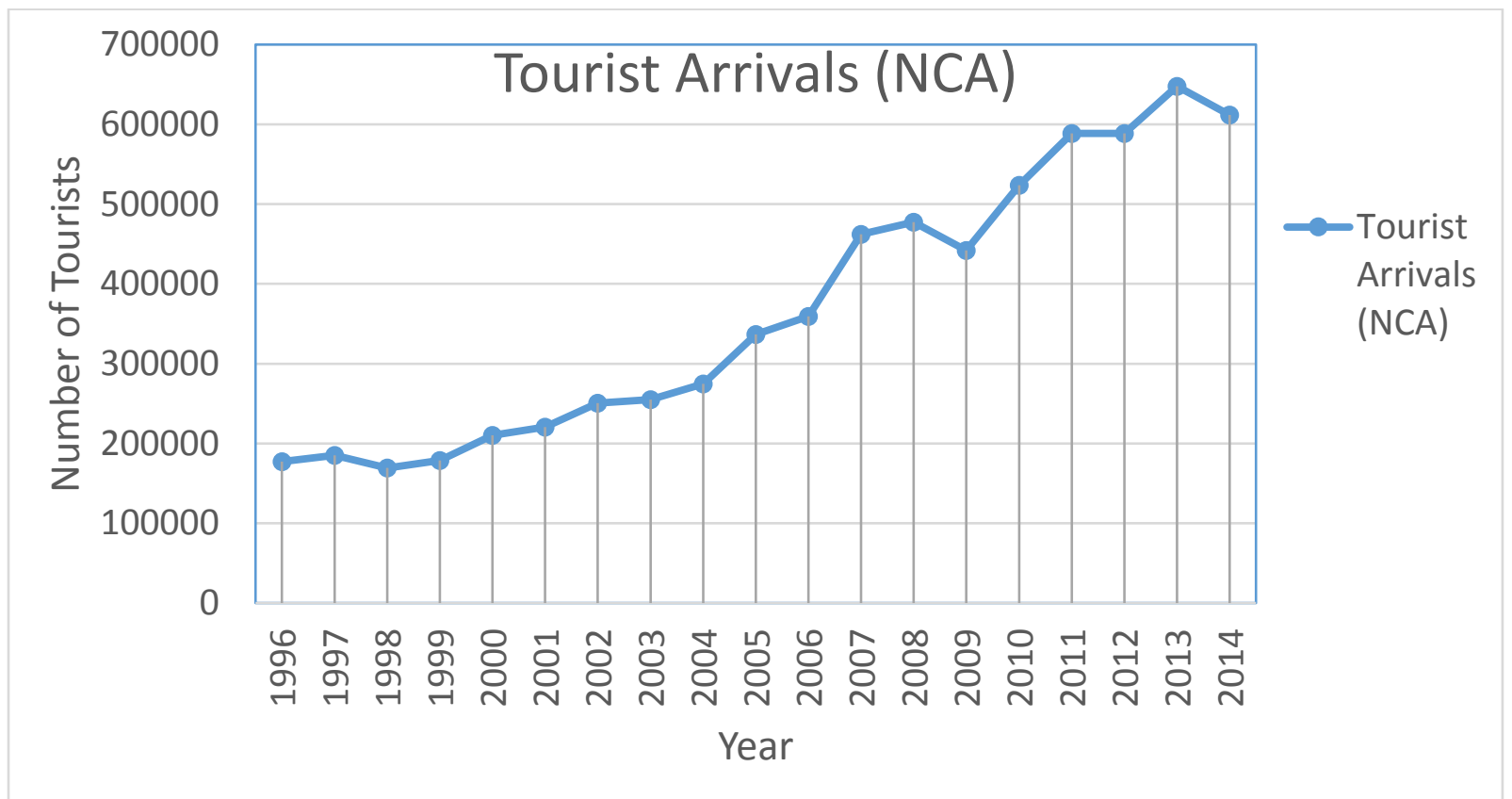

Figure 3. Annual tourists' arrivals for NCA (1996-2014).

A previous study conducted at NCA in 2007, examined the trends and impacts of vehicle crowding. The Norwegian Institute for Nature Research (NINA) conducted this study in collaboration with Ngorongoro Conservation Area Authority (NCAA). The 
comprehensive study focused on both the ecological impacts, as well as perceptions of tourists' in regards to vehicle congestion.

The findings of the ecological study document significant changes in wildlife behavior, especially when it comes to large mammals (lion, cheetah and rhino). Specific impacts to wildlife included genetic depression via inbreeding, fragmentation of the environment, disturbances of prey-predator relationship, lower hunting success, changes in caloric bank and increased resting time (Nyahongo et al., 2007). For example, lions have showed changes in reproductive activity, feeding time, preypredator relationship, and increased resting time due to artificial shade provided by safari vehicle congestion (Nyahongo et al., 2007).

The tourism study found that tourists were concerned with the level of vehicle crowding in the crater. When the tourists were requested to express their opinion regarding the effect of tourism on the environment of NCA, $73.9 \%$ of respondents $(\mathrm{N}=400)$ claimed, "Tourist vehicles have negative impact to NCA environment." Furthermore 72.5\% ( $\mathrm{N}=400)$ of respondents stated, "They would not visit Ngorongoro if the number of tourists in the park were doubled." (Nyahongo et al., 2007).

The NINA study recommended, "There should be a call for a NCAA management strategy to channel and control the number of tourist vehicles entering the crater per day and the amount of time spent per sighted carnivore surrounded by vehicles." The report also recommended that, "NCA Authority should (on a regular basis) inform 
stakeholders, tour operators and hotel companies about ecological effects of tourist activities on sensitive habitats and endangered species." (Nyahongo et al., 2007).

\section{Educational Messaging}

As discussed earlier, a sustainable approach to tourism encourages experiences that foster greater understanding, appreciation and conservation of the environment (Palmer \& Hoffman, 2001). An increasingly common practice for wildlife-area managers is to incorporate interpretive educational information as a part of the viewing experience (Keane et al., 2011). As a management practice, educational messaging aims to increase awareness and influence behavior of visiting tourist in a way that promotes environmental stewardship without deteriorating the quality of experience (Newsome et al., 2005).

\section{Photo-Based Surveys}

Numerous studies have utilized photo-based surveys to assess perceptions in natural settings (Cable et al., 1984; Habron, 1998). The use of photo-based surveys has been a subject of debated in the literature (Kroh \& Gimblett, 1992; Palmer \& Hoffman, 1997). An argument against the use of photo-based simulations is that they may be subject to external variables that influence interpretation (Palmer \& Hoffman, 1997). However, a growing number of studies (Daniel, 2001; Palmer \& Hoffman, 2001) support the use of images in survey research, especially when examining perceptions of "visual characteristics of a fairly typical natural environment" (Gimblett et al., 2000). Increasingly photo-based surveys utilize electronic platforms that provide several 
advantages to older, less effective, pencil and paper surveys (Garrote et al., 2011). For example, manipulation of photos to satisfy experimental design, real time data

monitoring, and simple user interface increase the ease of use for the participant (Brand et al., 2008). 
CHAPTER 3

METHODOLOGY

\section{Survey Content \& Design}

A photo-based survey instrument was developed and delivered to measure the impact of an educational intervention on tourists' perceived satisfaction in regards to wildlife viewing distance. The first section of the survey provided introductory text that informed the participant of the purpose of research, in addition to gathering demographic information that included; age, gender, education level, and income. Although all information was kept anonymous, respondents also had the "prefer not to disclose" option for any of the demographic questions they were not comfortable answering.

The next section of the survey gathered the "pre-intervention" scores. Voluntary participants rated 9 stock images, one photo at a time. Participants were prompted to rate each photo in regards to wildlife viewing distances represented in each photo. Participants rated their perceived quality of experience using a 5-point Likert scale ranging from 1: very dissatisfied to 5: very satisfied. An Information page provided instructions for responding to the stock images as well as an example of the rating scale (Figure 4). The participants rated each of the 9 images, one photo at a time. A randomized presentation of photos controlled for order bias. The 5-point preference scale appeared at the bottom of each photo. 

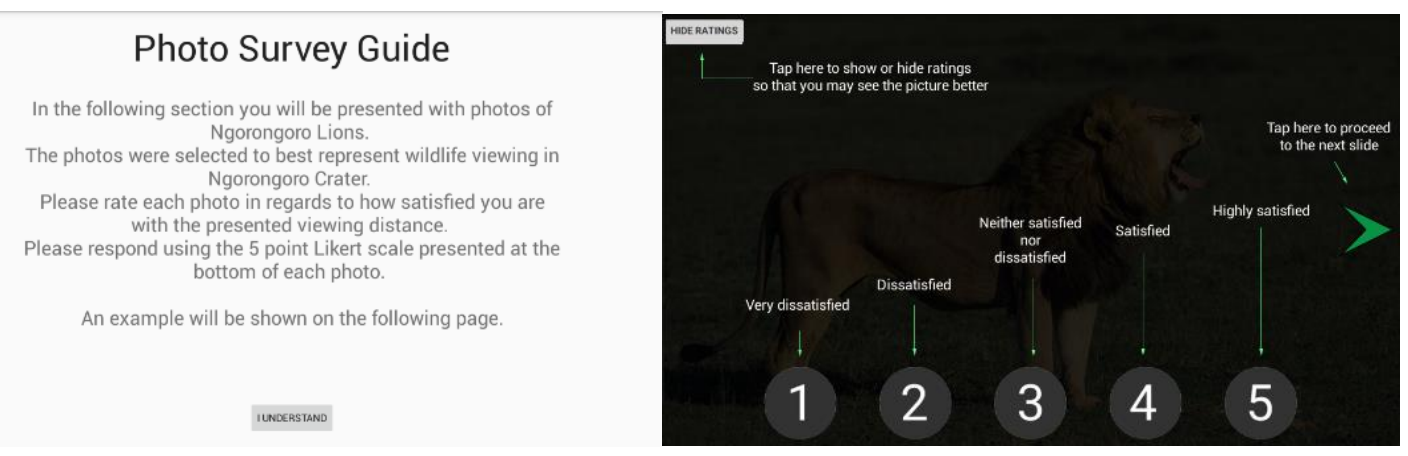

Figure 4. Example of photo survey guide and rating scale.

The survey photo selection aimed to identify photos representing the NCA lion viewing safari experience. The survey photo set included 9 stock images taken while on safari at NCA. Each of the survey images included a single female lion at varying distances. In order to isolate the proximity variable, the photos represented three different viewing distances (close, medium, far). Having multiple representations of each viewing distance made it possible to address the reliability of the survey instrument through inter item analysis. Specifically, this study utilized the Cronbach's alpha function to determine the consistency of photos in representing the intended viewing distance.

After rating all 9 photos, the participants were presented with intervention page that included educational information regarding the impacts of viewing lions at close proximities $(>5 \mathrm{~m})$. The educational intervention consisted of a short statement and bulleted list providing objective information regarding the impacts of increased touristvehicle crowding on lion behavior (Figure 5). Informed by previous research, the specific impacts included artificially affecting energy levels, disturbances in prey-predator 
relationship, decline in reproductive activity, and dependence on artificial shade cover (i.e., safari vehicles).

\section{Did you know?}

Previous research has shown that close viewing

distances $(<10 \mathrm{~m})$ to lions are linked to the following

impacts:

- Artificially affecting energy levels

- Disturbance in predator-prey relationship

- Decline in reproductive activity

- Further dependence on artificial shade cover

(safari vehicles)

Figure 5. Example of educational intervention page.

Following the educational intervention page, participant were prompted to once again rate the 9 photos. Although photos were presented in a randomized sequence, the database organized and linked responses to each individual photo. In other words, the order in which the photos were presented did not affect the order in which the responses were stored in the database. Once participants completed the postintervention section, they arrived on a debriefing page with the option to provide an email contact for updates and findings of the study.

\section{Piloting}

The survey instrument was piloted in order to address methodological challenges such as, image quality and composition, appropriate language within the survey, and reliability of data recording and storage. Central Washington University 
undergraduate students in the geography and anthropology departments piloted the survey instrument, as well as a random selection of students from student clubs involved with recreation and tourism activities. The survey instrument was also piloted by a small subset ( $n>20)$ of working professionals. The piloting process informed the decision to include a photo set of 9 images, opposed to 3 or 6 photos. Having multiple representations of each viewing distance made it possible to address the reliability of the survey instrument through inter-item analysis. Additionally, piloting informed changes to the language of the instruction and intervention page as well as identifying photos that best fit the purpose of the study.

\section{Sampling}

Survey research took place at the entrance of NCA over a 2-week period in January of 2016. To qualify for the study, the individual had to be participating in an organized safari-vehicle tour and be over the age of 18. Organized safari tours are required to stop at the entrance of NCA to present park officials with the appropriate permits prior to entering the conservation area. Surveys were administered throughout the parking lot and visitor center outside the conservation area entrance. All participants were surveyed prior to their NCA safari experience to control for pre-trip responses. Surveys were administered by the principal investigator and a graduate assistant using a language script approved by Central Washington University Human Subjects Review council. Tourists were asked if they were interested in participating in a voluntary 5-minute survey to help inform park policy. Eligible volunteers were provided with verbal information to clarify the purpose of the study and instructions for 
responding to the survey. The field research team also included a Tanzania Wildlife Research Institute (TAWARI) research scientist and his research assistant. Having native Tanzanians as a part of the research team was helpful in gaining the necessary permits and establishing credibility and clear communication with park officials and guides in order to access the population of interest.

Data from the digital questionnaires were downloaded daily and analyzed to track reliability of the survey instrument throughout the process. All completed survey data was stored on the tablets, micro SD cards, a research laptop, and a cloud database to ensure redundancy in the event that tablets were damaged during fieldwork. In order to comply with Human Subjects Review Council (IRB) Guidelines for anonymity, the responses were organized by numeric I.D.s within the database so that no personal information could be identified and linked to the responses of a participant.

\section{Data Analysis}

\section{Survey Reliability}

A vital part of the survey design was ensuring stock images were consistent in representing the three wildlife viewing distances (close, medium, far). Cronbach's alpha is a statistical calculation that estimates the reliability of survey instruments; specifically it tests for internal consistency of the survey instrument. The results of this test are presented as a coefficient ranging from .00 to 1.0, with .00 representing (no consistency) and 1.0 representing (perfect consistency). In general, the acceptable range 
of Cronbach alpha scores is $.70-.95$, with the sample size and nature of research influencing the interpretation of these scores (Tavakol \& Dennick, 2011).

The Cronbach's alpha scores determined how consistent responses were across each proximity group. For example, the pre-intervention responses to "close" images (photo 1 , photo 2 , photo 3 ) were analyzed to see how consistently they represented the same construct, which in this case was the proximity variable for "close" viewing distances. The reliability function tested for pre and post intervention responses within each proximity group. If the Cronbach's alpha analysis had shown any photo to be an outlier, it was excluded due to the 9-photo survey design without compromising the entire study.

\section{Educational Intervention Impact Analysis}

Once the reliability of the survey instrument was determined, it was possible to address the focus of this research: the effectiveness of educational intervention measure. In order to understand the effect of the intervention, a two-sample $t$-test, as well as the Wilcoxon ranked sum test calculated the amount of change between pre and post intervention responses. The Wilcoxon test is a non-parametric test similar to a $t$ test but analyses ordinal data sets by ranking the response score medians rather than calculating means. This test is ideal for comparing nonparametric statistics commonly derived from preference scales scores. The Wilcoxon test examines ordinal data sets where the difference between values may not be consistent. For example, on a 5-point Likert scale it cannot be assumed that the difference between 1 (highly dissatisfied) and 
2 (dissatisfied) is equal to the difference between 2 (dissatisfied) and 3 (neither satisfied nor dissatisfied). The distribution of an individual's preference is not numerically uniform and therefore interpretation must consider this assumption.

\section{Proximity Group Analysis}

To gain a deeper understanding the impacts of educational intervention the 9 photos were divided into three respective groups (close, medium, and far). The mean satisfaction score of each individual participant was calculated within each photo grouping, providing a single score for each proximity group. This was done for pre- and post-intervention satisfaction scores, resulting in six sub groups used to further examine the impact of intervention. Figure 6 provides an example of how the score were calculated for each participant. The highlighted numbers in Figure 6 provides an example of one respondent's adjusted scores for the new grouping scheme. The twosample $t$-test and Wilcoxon rank sum test were ran once again using the adjusted scores. 


\begin{tabular}{|c|c|c|c|c|c|c|c|c|}
\hline \multicolumn{9}{|c|}{ Pre-Intervention Satisfaction Scores } \\
\hline \multicolumn{3}{|c|}{ Close } & \multicolumn{3}{|c|}{ Medium } & \multicolumn{3}{|c|}{ Far } \\
\hline Photo 1 & Photo 2 & Photo 3 & Photo 4 & Photo 5 & Photo 6 & Photo 7 & Photo 8 & Photo 9 \\
\hline 3 & 4 & 4 & 5 & 5 & 4 & 4 & 4 & 5 \\
\hline \multicolumn{3}{|c|}{ Mean=3.66 } & \multicolumn{3}{|c|}{ Mean=4.66 } & \multicolumn{3}{|c|}{ Mean $=4.33$} \\
\hline \multicolumn{9}{|c|}{ Educational Intervention Treatment } \\
\hline \multicolumn{9}{|c|}{ Post-Intervention Satisfaction scores } \\
\hline \multicolumn{3}{|c|}{ Close } & \multicolumn{3}{|c|}{ Medium } & \multicolumn{3}{|c|}{ Far } \\
\hline Photo 1 & Photo 2 & Photo 3 & Photo 4 & Photo 5 & Photo 6 & Photo 7 & Photo 8 & Photo 9 \\
\hline 1 & 2 & 1 & 2 & 3 & 4 & 5 & 5 & 4 \\
\hline \multicolumn{3}{|c|}{ Mean= 1.33} & \multicolumn{3}{|c|}{ Mean= 3} & \multicolumn{3}{|c|}{ Mean= 4.66} \\
\hline
\end{tabular}

Figure 6. Single participant mean score example. 


\section{References}

Ballantyne, R., Packer, J., Hughes, K. and Dierking, L. (2007). Conservation learning in wildlife tourism settings: lessons from research in zoos and aquariums. Environmental Education Research, 13(3), 367-383.

Ballantyne, R., Packer, J., \& Hughes, K. (2009). Tourists' support for conservation messages and sustainable management practices in wildlife tourism experiences. Tourism Management, 30(5), 658-664.

Bhatta, K. D. (2014). Ecotourism planning and sustainable community development in Nepal. HKU Theses Online (HKUTO).

Brand, U., Görg, C., Hirsch, J., \& Wissen, M. (2008). Conflicts in environmental regulation and the internationalization of the state: contested terrains. New York: Routledge.

Brohman, J. (1996). New directions in tourism for third world development. Annals of Tourism Research, 23(1), 48-70.

Brundtland, G., Khalid, M., Agnelli, S., Al-Athel, S., Chidzero, B., Fadika, L., \& Singh, M. (1987). Our common future: Brundtland Report.

Butler, R. W. (1992). Alternative tourism: The thin edge of the wedge. In V. L. Smith \& W. R. Eadington (Eds.), Tourism alternatives: Potentials and pitfalls in the development of tourism (pp. 31-46). Philadelphia: University of Pennsylvania Press and the International Academy for the Study of Tourism.

Cable, T. T., Knudson, D. M., \& Stewart, D. J. (1984). The economic benefits to visitors of an interpretive facility. The Journal of Environmental Education, 15(4), 32-37.

Center for Responsible Travel (CREST). (2014). Rights and Responsibilities: A Compilation of Codes of Conduct for Tourism and Indigenous and Local Communities. Indigenous Tourism, (pp. 22-24).

Comaroff, J., \& Comaroff, J. L. (2001). Millennial capitalism and the culture of neoliberalism. Duke University Press.

Cousins, J. A. (2007). The role of UK-based conservation tourism operators. Tourism Management, 28(4), 1020-1030.

Cunningham, Victoria; Haji, Mahjabeen; Morisset, Jacques. (2015). Tanzania economic update: the elephant in the room - unlocking the potential of the tourism industry for Tanzanians. Tanzania economic update; issue no. 6. Washington, DC: World Bank Group. http://documents.worldbank.org/curated/en/716911468305677763/Tanzaniaeconomic-update-the-elephant-in-the-room-unlocking-the-potential-of-the-tourismindustry-for-Tanzanians 
Daniel, T. C. (2001). Whither scenic beauty? Visual landscape quality assessment in the 21 st century. Landscape and urban planning, 54(1), 267-281.

Di Minin, E., Fraser, I., Slotow, R., \& MacMillan, D. C. (2013). Understanding heterogeneous preference of tourists for big game species: implications for conservation and management. Animal Conservation, 16(3), 249-258.

Durant, S. M., Craft, M. E., Hilborn, R., Bashir, S., Hando, J., \& Thomas, L. (2011). Long-term trends in carnivore abundance using distance sampling in Serengeti National Park, Tanzania. Journal of Applied Ecology, 48(6), 1490-1500.

Falk, J. H. (2011). The learning tourist: The role of identity-related visit motivations. Tourism in Marine Environments, 7(3-4), 223-232.

Falk, J. H., Ballantyne, R., Packer, J., \& Benckendorff, P. (2012). Travel and learning: A neglected tourism research area. Annals of Tourism Research, 39(2), 908-927.

France, L. A. (1997). The Earthscan reader in sustainable tourism. Earthscan Publications Ltd.

Fryxell, J. M., Mosser, A., Sinclair, A. R., \& Packer, C. (2007). Group formation stabilizes predator-prey dynamics. Nature, 449(7165), 1041-1043.

Garland, E. (2008). The elephant in the room: confronting the colonial character of wildlife conservation in Africa. African Studies Review, 51(03), 51-74.

Garrote, G., De Ayala, R. P., Pereira, P., Robles, F., Guzman, N., García, F. J., \& Barroso, J. L. (2011). Estimation of the Iberian lynx (Lynx pardinus) population in the Doñana area, SW Spain, using capture-recapture analysis of camera-trapping data. European Journal of Wildlife Research, 57(2), 355-362.

Gimblett, R., Daniel, T., \& Meitner, M. J. (2000). An individual-based modeling approach to simulating recreation use in wilderness settings. In: Cole, David N.; McCool, Stephen F.; Borrie, William T.; O'Loughlin, Jennifer, comps. 2000. Wilderness science in a time of change conference-Volume 4: Wilderness visitors, experiences, and visitor management; 1999 May 23-27; Missoula, MT. Proceedings RMRS-P-15-VOL-4. Ogden, UT: U.S. Department of Agriculture, Forest Service, Rocky Mountain Research Station. p. 99-106

Gössling, S., Hall, C. M., \& Weaver, D. (Eds.). (2009). Sustainable tourism futures: Perspectives on systems, restructuring and innovations. New York: Routledge.

Habron, D. (1998). Visual perception of wild land in Scotland. Landscape and urban Planning, 42(1), 45-56.

Hall, C. M., \& Lew, A. A. (1998). Sustainable tourism. A geographical perspective. Addison Wesley Longman Ltd.

Hawkins, D. E., Ruddy, J., \& Ardah, A. (2012). Reforming Higher Education: The Case of Jordan's Hospitality and Tourism Sector. Journal of Teaching in Travel \& Tourism, 12(1), 105-117. 
Higginbottom, K. (2004). Managing impacts of wildlife tourism on wildlife. Wildlife tourism: Impacts, management and planning, 211-29.

Higginbottom, K., Green, R., \& Northrope, C. (2003). A framework for managing the negative impacts of wildlife tourism on wildlife. Human Dimensions of Wildlife, 8(1), 1-24.

Hopcraft, J. G. C., Sinclair, A. R. E., \& Packer, C. (2005). Planning for success: Serengeti lions seek prey accessibility rather than abundance. Journal of Animal Ecology, 74(3), 559-566.

The International Ecotourism Society (2015). TIES Press release: Ecotourism Principles Revision. https://www.ecotourism.org/news/ties-announces-ecotourism-principles-revision.

Keane, A., Ramarolahy, A. A., Jones, J. P., \& Milner-Gulland, E. J. (2011). Evidence for the effects of environmental engagement and education on knowledge of wildlife laws in Madagascar. Conservation Letters, 4(1), 55-63.Kroh, D. P., \& Gimblett, R. H. (1992). Comparing live experience with pictures in articulating landscape preference. Landscape Research, 17(2), 58-69.

Kroh, D. P., \& Gimblett, R. H. (1992). Comparing live experience with pictures in articulating landscape preference. Landscape Research, 17(2), 58-69.

Liburd, J. J., \& Edwards, D. (Eds.). (2010). Understanding the sustainable development of tourism. Oxford: Goodfellow.Melita, A. W., \& Mendlinger, S. (2013). The Impact of Tourism Revenue on the Local Communities' Livelihood: A Case Study of Ngorongoro Conservation Area, Tanzania. Journal of Service Science and Management, 6(1), 117.

Moscardo, G. (2009). Tourism and quality of life: Towards a more critical approach. Tourism and Hospitality Research, 9(2), 159-170.

Mosser, A., \& Packer, C. (2009). Group territoriality and the benefits of sociality in the African lion, Panthera Leo. Animal Behavior, 78(2), 359-370.

Mowforth, M., \& and Munt, I. (2009). Tourism and sustainability: Development, globalization and new tourism in the Third World (3rd ed). London, UK and New York, USA: Routledge.

Nepal, S. K. (1997). Sustainable tourism, protected areas and livelihood needs of local communities in developing countries. The International Journal of Sustainable Development \& World Ecology, 4(2), 123-135.

Newsome, D., Lewis, A., \& Moncrieff, D. (2004). Impacts and risks associated with developing, but unsupervised, stingray tourism at Hamelin Bay, Western Australia. The International Journal of Tourism Research, 6(5), 305.

Newsome, D., Dowling, R. K., \& Moore, S. A. (2005). Wildlife tourism (Vol. 24). Channel View Publications.

Ngorongoro Conservation Area (NCA). (2016). In Encyclopædia Britannica. Retrieved fromhttps://www.britannica.com/place/Ngorongoro-Conservation-Area 
Nyahongo, J., Lowassa, A., Malugu, L., Nkya, H., Mwakalebe, G., Thomassen, J., Kaltenborn, B. P., Lyamuya, R., Marealle, W., Keyyu, J., Stokke, S. \& Røskaft, E. 2007. The effects of vehicle congestion on the environment - an EIA in the Ngorongoro crater. The Environmental Impact Statement - NINA Report 258. 83 pp.

Palmer, J. F., \& Hoffman, R. E. (2001). Rating reliability and representation validity in scenic landscape assessments. Landscape and urban planning,54(1), 149-161.

Palmer, A. R., \& Hoffman, M. T. (1997). Nama-karoo. Vegetation of Southern Africa, 167, 186.

Panitchpakdi, K. (2012). Analyzing sustainability of a local community by EBS theory: The case of Kao Yi Sarn, Samut Songkram, Thailand. Journal of ASIAN Behavioural Studies. 13(3) 116.

Pearce, D. (1992). Alternative tourism: Concepts, classifications and questions. In V. Smith and W. Eadington (Eds.), Tourism alternative: Potentials and problems in the development of tourism (pp.15-30). Philadelphia: University of Pennsylvania Press.

Powell, R. B., Kellert, S. R., \& Ham, S. H. (2009). Interactional theory and the sustainable naturebased tourism experience. Society and Natural Resources, 22(8), 761-776.

Rodger, K., Moore, S. A., \& Newsome, D. (2007). Wildlife tours in Australia: Characteristics, the place of science and sustainable futures. Journal of Sustainable Tourism, 15(2), 160-179.

Rostow, W. (1960). The stages of economic growth: A non-communist manifesto (2nd ed.). Cambridge: Cambridge University Press.

Scheyvens, R. (2002). Tourism for development: empowering communities. Essex: Pearson Education Limited.

Schumacher, E. F. (1973). Small is beautiful: Economics as if people mattered. New York: Harper \& Row

Semeniuk, C. A., Haider, W., Beardmore, B., \& Rothley, K. D. (2009). A multi-attribute trade-off approach for advancing the management of marine wildlife tourism: a quantitative assessment of heterogeneous visitor preferences. Aquatic Conservation: Marine and Freshwater Ecosystems, 19(2), 194.

Skinner, A. R., Hay, R. L., Masao, F., \& Blackwell, B. A. B. (2003). Dating the Naisiusiu Beds, Olduvai Gorge, by electron spin resonance. Quaternary Science Reviews, 22(10), 13611366.

Tavakol, M., \& Dennick, R. (2011). Making sense of Cronbach's alpha.International journal of medical education, 2, 53.

Telfer, D. J., \& Sharpley, R. (2008). Tourism and Development in the Developing World. Abingdon (Oxon) and New York: Routledge.

Telfer, D. J. (2002). The evolution of tourism and development theory. In R. Sharpley \& D. J. Telfer (Eds.), Tourism and development: Concepts and issues (pp. 35-78). Clevedon, UK: Channel View Publication 
United Nations World Tourism Organization (UNWTO). (2006) UNWTO's Declaration on Tourism and the Millennium Goals: Harnessing Tourism for the Millennium Development Goals; Madrid, Spain: UNWTO.

Williams, P. H., Burgess, N. D., \& Rahbek, C. (2000). Flagship species, ecological complementarity and conserving the diversity of mammals and birds in sub-Saharan Africa. Animal Conservation, 3(3), 249-260.

World Tourism \& Travel Council (WTTC). (2015). Travel \& Tourism: Economic Impact 2015, Tanzania; WTTC: London, UK. 
JOURNAL ARTICLE

SUSTAINABLE SAFARI PRACTICES: PROXIMITY TO WILDLIFE,

EDUCATIONAL INTERVENTION AND

THE QUALITY OF EXPIRIENCE

by

Ryan Devine Tarver

July 2016

\begin{abstract}
This research examines the perceived quality of experience for safari tourists in relation to wildlife viewing proximities and the potential of educational interventions as a management strategy to mitigate adverse impacts of safari participant crowding. Crowding emanates from the safari tourist preferences to obtain close proximity to animals, particularly large mammals. Recognizing these preferences and associated impacts to animal behavior defined in previous research, we develop and deliver a survey instrument designed to measure the perceived quality of experience of the safari tourist while controlling for the viewing proximity variable. The survey instrument involves responding to stock photos selected to represent the safari-tour experience, using a Likert type rating scale. Using a "pre-treatment" and "post treatment" protocol, we share an educational management intervention that correlates the impact of intervention on safari participants' perceptions of the quality of safari experience based on proximity to animals.
\end{abstract}




\title{
SUSTAINABLE SAFARI PRACTICES: PROXIMITY TO WILDLIFE, EDUCATIONAL INTERVENTION AND THE QUALITY OF EXPERIENCE
}

\author{
Ryan Tarver
}

\section{Introduction}

This research examines the impact of an educational intervention on safari goer's perceptions of the quality of their experience as it relates to their perceived physical proximity to lions in the Ngorongoro Crater. Within the broader sustainable tourism context, the implications of this relationship are extensive. Sustainable tourism is an approach to tourism "that takes full account of its current and future economic, social and environmental impacts, addressing the needs of visitors, the industry, the environment and host communities" (UNWTO, 2006). Economically, tourism is considered to be a reliable industry (Hawkins et al., 2012), thus many developing countries utilize tourism as a vehicle for economic growth (Panitchpakdi, 2012). Notably, Tanzania generates $11.8 \%$ of its GDP through tourism activity, ranking as the countries' single largest industry (Cunningham et al., 2015). Tanzania experienced a record number

of international arrivals $(1,113,000)$ in 2014 (WTTC, 2015) (Figure 1). The tourism sector directly employs over 450,000 native Tanzanians and indirectly generates about 1.2 million jobs (Cunningham et al., 2015). Wildlife tourism, specifically safari-related tourism, is the predominant form of tourism in Tanzania (WTTC, 2015). As an economic engine, safaris have the capacity to provide a steady source of revenue as long as the safari experience predictably satisfies safari tourism customers (Gössling et al., 2009). 
In the context of sub-Sahara wildlife viewing, the "big five" are the centerpiece of the nature-based tourism experience (Melita \& Mendlinger, 2013). Namely, the five species include the African lion (Panthera leo), leopard (Panthera pardus), elephant (Loxodonta africana), buffalo (Syncerus caffer), and black rhino (Diceros bicornis) (Williams et al., 2000). The proximity at which tourists view these species of interest also contributes to the quality of experience for safari tourist (Moscardo et al., 2001; Semenuik et al., 2009). The preference to view these species has resulted in higher revenues, greater visitation, more predominant public profiles, and more conservation attention for protected areas that provide habitat for the big five (Higginbottom et al., 2003). For the tourists, the wildlife viewing experience can lead to greater awareness, appreciation and connection to nature, and a heightened sense of personal responsibility when it comes to the state of the environment (Ballantyne et al., 2007; Falk et al., 2012; Powell et al., 2009).

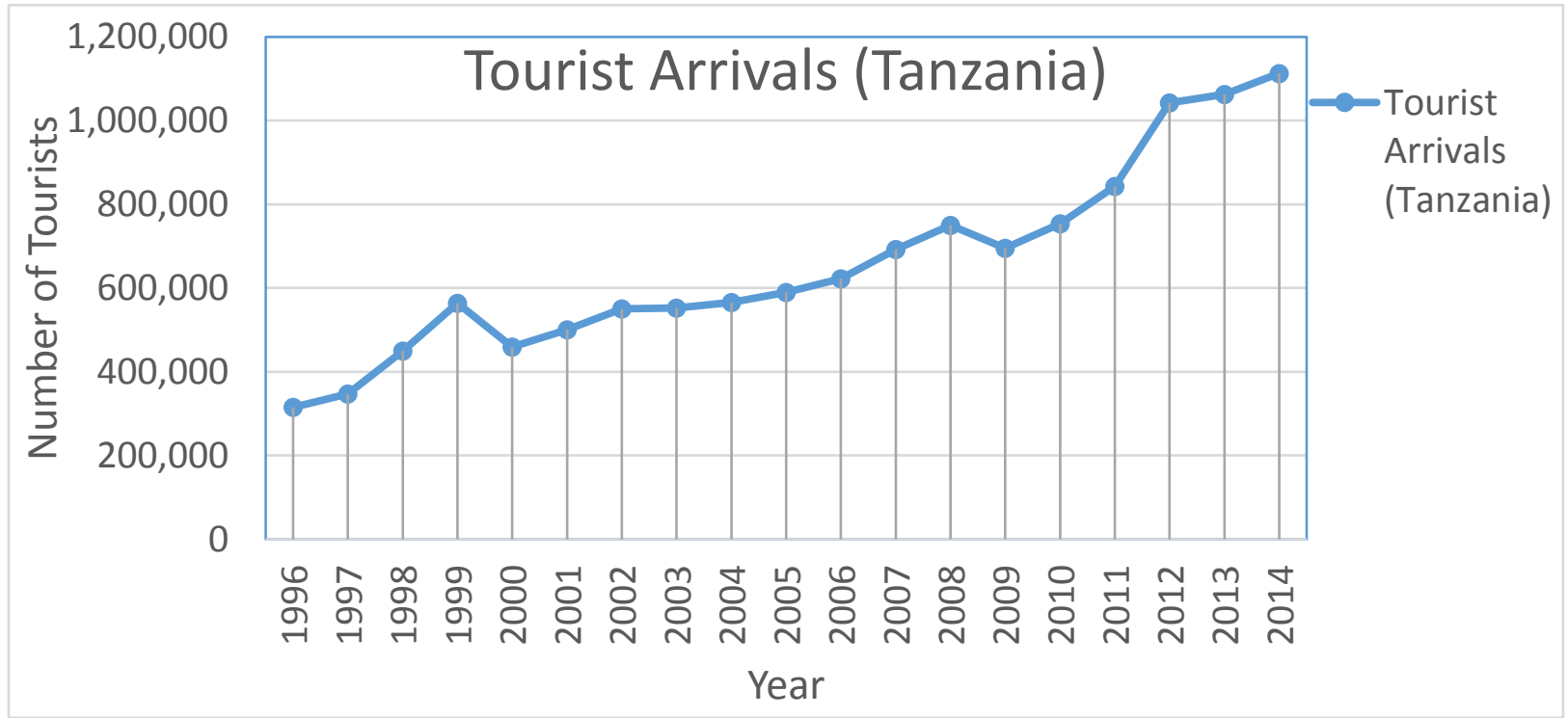

Figure 1. Annual tourist arrivals for Tanzania 1996-2014. (WTTC, 2015) 
However, not all outcomes from safari tourism activity are positive. Several studies report that flagship species, like the big five, are more vulnerable to experience adverse impacts due to the preference to view them, especially at close proximities (Durant et al., 2011; Mosser \& Packer, 2009; Fryxell et al., 2007; Hopcraft et al., 2005). For example, lions have experienced changes in reproductive activity, feeding time, prey-predator relationship, and increased resting time due to artificial shade provided by safari vehicle congestion (Nyahongo et al., 2007).

Wildlife area managers face the challenge of preserving the species responsible for generating tourism revenue, without compromising the quality of experience for the safari customer (Melita \& Mendlinger, 2013). If the quality of experience significantly and persistently deteriorates, the safari industries' ability to compete in the international tourism sector could be compromised. Herein lies the paradox central to this research; if tourist proximity to flagship species (lions) negatively influences behavior and propagation, how can the resource i.e., lions (and the biotic community necessary to sustain their viability) be sustained without negatively affecting the quality of the experience of the safari customer?

To answer this question, this case study utilizes survey research methodology with a photo imagery platform to measures the impact of an educational intervention on tourists' perceptions of the quality of experience in relation to viewing distance. Ultimately, this study aims to provide Ngorongoro Conservation Area (NCA) management with data that indicates safari goers' preferences in order to substantiate 
practices that may better preserve the wildlife resource as well as the quality of experience for the safari tourists.

\section{Ngrorongoro Conservation Area: A Case Study}

Ngorongoro Conservation Area (NCA) served as boundaries for this case study. Established in 1959 as a multiple use area, NCA had the goal of hosting an indigenous population as well as protecting native wildlife (NCA, 2016). Covering 8,292 square kilometers $\left(\mathrm{KM}^{2}\right)$ of northern Tanzania (Figure 2), NCA is commonly referred to as "Africa's Eden," due to the array of wildlife, people, landscape and historic archeological sites that are found here (Garland, 2008). The abundant wildlife seen at NCA stems from a diverse habitat comprised of grassland plains, savanna woodland, forest, mountains, volcanic craters, lakes, rivers, and swamplands (NCA, 2016). NCA is home to the world's largest ungulate herds consisting of wildebeest, zebras, and gazelles. The predatory animal population includes lions, spotted hyenas, leopards, and cheetahs. NCA also provides habitat for the endangered black rhino, as well as, 400 species of birds (NCA, 2016).

\section{Ngorongoro Crater}

The primary tourist attraction of NCA is the Ngorongoro crater. According to archeological data, Ngorongoro Crater formed about 2.5 million years ago following the collapse of an active volcano (Skinner et al., 2003). The collapse of the volcano resulted in 264 square $\mathrm{km}\left(\mathrm{KM}^{2}\right)$ caldera that ranges $16-19 \mathrm{~km}$ across. The densely forested outer rim of the caldera quickly rises about 610 meters above the grasslands of the crater 
floor (NCA, 2016). This unique topography has created a contained environment favorable for wildlife viewing, especially at close proximities. A significant portion of the wildlife population is migratory, although a sufficient non-migratory wildlife population allows for year-round wildlife viewing opportunities.

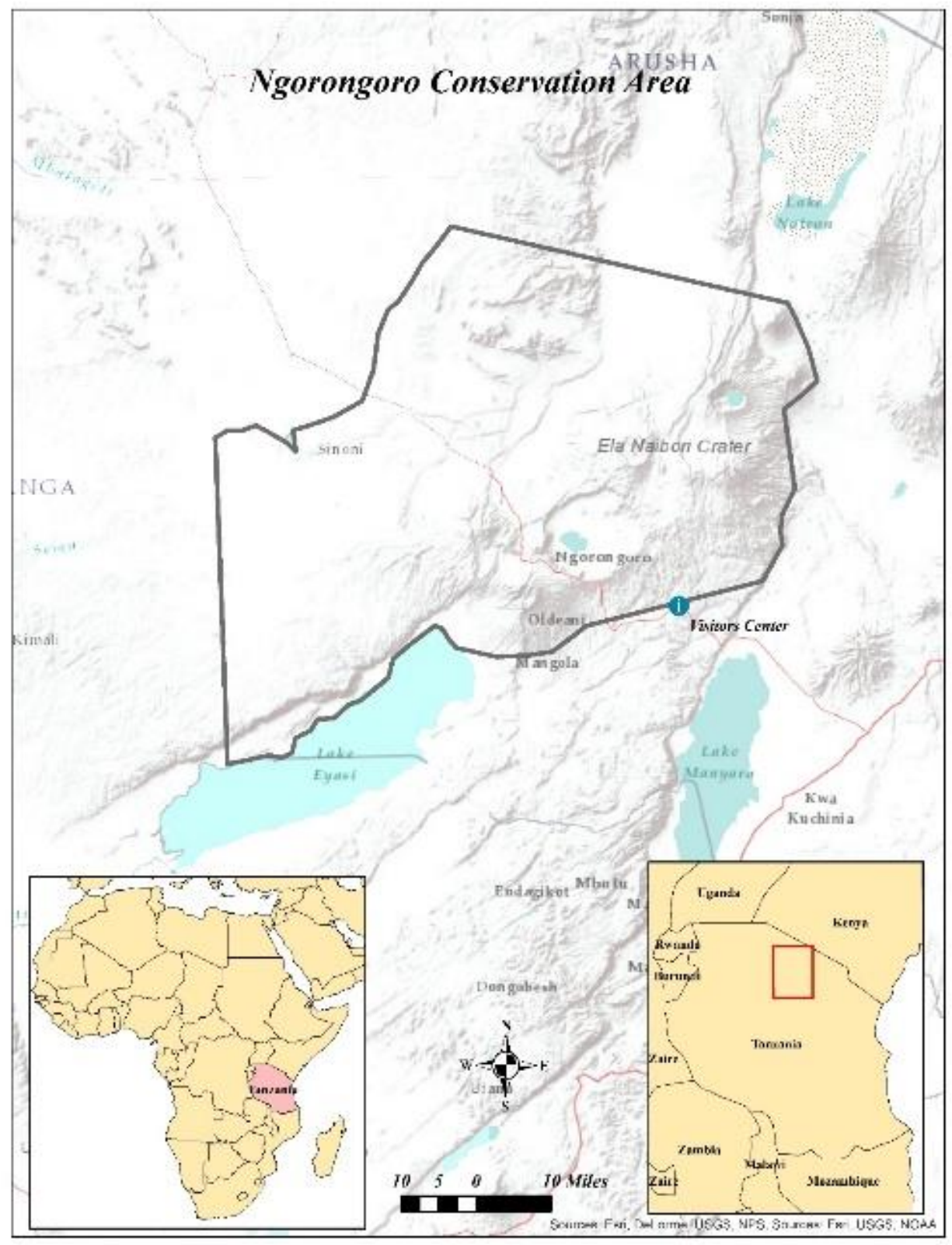

Figure 2. Location of Ngorongoro Conservation Area. 
The draw and economic potential of NCA through organized safari tourism does not come without its challenges. As visitation continues to increase for NCA (Figure 3), so does the congestion and exposure of humans to wildlife. The current trend has resulted in overcrowding of tourist vehicles (Nyahongo et al., 2007). The issue of overcrowding can lead to increased environmental degradation (Nyahongo et al., 2007).

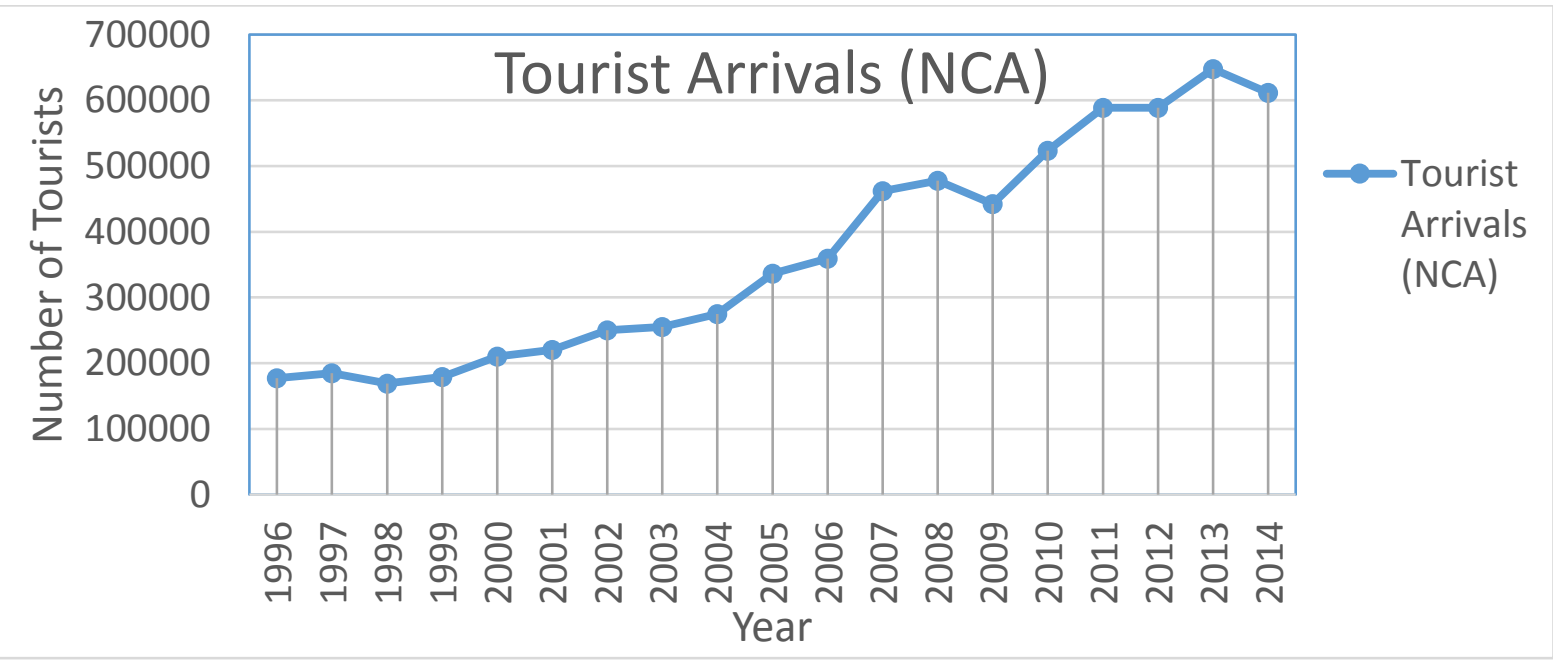

Figure 3. NCA annual tourists' arrivals (1996-2014).

\section{Methodology}

\section{Photo-Based Surveys}

Numerous studies have utilized photo-based surveys to assess perceptions in natural settings (Habron, 1998; Van den Berg et al., 2003). The use of photo-based perception surveys has been a subject of debated in the literature (Kroh \& Gimblett., 1992; Palmer \& Hoffman, 2001). It is argued that photo-based simulations may be subject to external variables that influence interpretation (Palmer \& Hoffman, 1997). 
However, a growing number of studies (Daniel, 2001; Palmer and Hoffman, 2001)

support the use of images in survey research, especially when examining perceptions of "visual characteristics of a fairly typical natural environment" (Gimblett et al., 2000). Increasingly photo-based surveys utilize electronic platforms that provide several advantages to older, less effective, pencil and paper surveys (Garrote et al., 2011). For example, manipulation of photos to satisfy experimental design, real time data monitoring, and simple user interface increase the ease of use for the participant (Brand et al., 2008).

\section{Survey Content}

A photo-based survey instrument was developed and delivered to measure the impact of an educational intervention on tourists' wildlife viewing distance preferences. The photos included in the survey were selected to represent the NCA lion viewing experience. The survey photo set included nine stock images taken while on safari at NCA. Each of the survey images included a single female lion at varying distances. In order to isolate the proximity variable, the photos were selected to represent three different viewing distances, with three images representing each distance. Having multiple representations of each viewing distance made it possible to address the reliability of the survey instrument through inter item analysis. Specifically, Cronbach's alpha was used to determine the consistency of photos in representing the intended viewing distance. 


\section{Survey Design}

The first section of the survey provided introductory text that informed the participant of the purpose of research, in addition to gathering demographic information including age, gender, education level, and income. Although all information was kept anonymous, respondents also had the "prefer not to disclose" option for any of the demographic questions they were not comfortable answering.

The next section of the survey gathered "pre-intervention" scores. The voluntary participants were prompted to rate nine stock images, one photo at a time, in regards to wildlife viewing distances represented in each photo. Participants rated their perceived quality of experience using a 5-point Likert scale ranging from 1: very dissatisfied to 5: very satisfied. An information page provided instructions for responding to the stock images as well as an example of the rating scale (Figure 4). The photos were presentenced in a randomized sequence to control for order bias. The 5-point preference scale appeared at the bottom of each photo.

\section{Photo Survey Guide}

In the following section you will be presented with photos of Ngorongoro Lions. Ngorongoro Crater.

Please rate each photo in regards to how satisfied you are with the presented viewing distance. bottom of each photo.

An example will be shown on the following page.

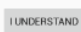
政 Please respond using the 5 point Likert scale presented at the

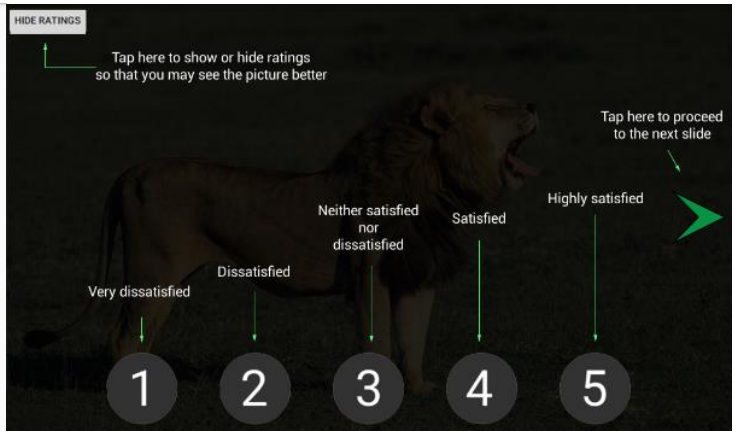

Figure 4. Example of photo survey guide and rating scale. 
After rating each of the nine photos, the participants were presented with intervention page that included educational information regarding the impacts of viewing lions at close proximities ( $>5 \mathrm{~m}$ ) (Figure 5). The educational intervention consisted of a short statement and bulleted list providing objective information regarding the impacts of increased tourist-vehicle crowding on lion behavior. Informed by previous research, the specific impacts included artificially affecting energy levels, disturbances in prey-predator relationship, decline in reproductive activity, and dependence on artificial shade cover provided by safari tour vehicles.

\section{Did you know?}

Previous research has shown that close viewing distances $(<10 \mathrm{~m})$ to lions are linked to the following impacts:

- Artificially affecting energy levels

- Disturbance in predator-prey relationship

- Decline in reproductive activity

- Further dependence on artificial shade cover (safari vehicles)

Figure 5. Example of educational intervention page.

Following the educational intervention page, participants were prompted to once again rate the nine photos. Although the photos were presented in a randomized sequence, the database organized and linked responses to each individual photo. In other words, the order in which the photos were presented did not affect the order in which the responses were stored in the database. Once the participant completed the 
post-intervention section, they arrived on a debriefing page with the option to provide an email contact for updates and findings of the study

\section{Piloting}

The survey instrument was piloted in order to address methodological challenges such as image quality and composition, appropriate language within the survey, and reliability of data recording and storage. Central Washington University undergraduate students in the geography and anthropology departments piloted the survey instrument, as well as a random selection of students from student clubs involved with recreation and tourism activities. The survey instrument was also piloted by a small subset $(n>20)$ of working professionals. The piloting process informed the decision to include a photo set of nine images, opposed to three or six photos as smaller photo sets did not allow for identifying outlier photos through inter-item analysis. Additionally, piloting informed changes to the language of the instruction and intervention page, as well as identifying photos that best fit the purpose of the study.

\section{Sampling}

Survey research was conducted at the entrance of NCA over a two-week period in January of 2016. To qualify for the study, an individual had to be participating in an organized safari-vehicle tour and be over the age of 18. Organized safari tours are required to stop at the entrance of NCA to present park officials with the appropriate permits prior to entering the conservation area. Survey data was collected throughout the parking lot and visitor center outside the conservation area entrance. All 
participants were surveyed prior to their NCA safari experience to control for pre-trip responses. Surveys were administered by the principal investigator and a graduate assistant using a language script approved by the Central Washington University Human Subjects Review council. Tourists were asked if they were interested in participating in a voluntary 5-minute survey to help inform park policy. Eligible volunteers were provided with verbal information addressing the purpose of the study and instructions for responding to the survey. The field research team also included a Tanzania Wildlife Research Institute (TAWARI) research scientist and his research assistant. Having native Tanzanians as a part of the research team was helpful in gaining the necessary permits and establishing credibility and clear communication with park officials and guides.

Data from the digital questionnaires were downloaded daily and analyzed to track reliability of the survey instrument throughout the process. Completed surveys were stored on the tablets, micro SD cards, a research laptop, and a cloud database to ensure redundancy in the event that tablets were damaged during fieldwork. In order to comply with Central Washington University Human Subjects Review Council (IRB) Guidelines for anonymity, the responses were organized by numeric I.D.'s within the database so that no personal information could be identified and linked to the participants.

\section{Survey Reliability}

As discussed earlier, critics of photo-based surveys question the reliability of the photo's included in the survey instrument. Therefore, to test for internal-reliability of 
the survey instrument, Cronbach's alpha coefficient were calculated for each group of photos. This determined the consistency of the survey photos in representing a given viewing distance. Previous research identifies Cronbach's alpha as a useful coefficient for assessing internal consistency of a survey instrument (Bland \& Altman, 1997). The results of the Cronbach alpha calculation are coefficients ranging from zero (no consistency) to 1 (absolute consistency) (Tavakol \& Dennick, 2011). The acceptable range of scores depends of the context of the study but for the purpose of comparing groups a satisfactory score falls between $\alpha=0.7$ to 0.95 (Tavakol \& Dennick ,2011). When looking at Table 1 note that, five of the six coefficient scores fall within the acceptable range. The pre-education score for the medium group of $\alpha=0.63$ is outside the acceptable range, although this is still a strong score and was deemed acceptable in the context of this study.

In order to show that the consistency demonstrated here is due to intra-group similarity, rather than consistency over the set of nine images, Cronbach's alpha was also run using a photo from each of the three proximity groups. Table 2 shows that no such "overall consistency" exists; that is, each of the three sets of images does indeed capture a different viewing experience. 
Table 1. Survey internal consistency scores (Cronbach's alpha)

\begin{tabular}{|c|c|c|c|}
\hline \multicolumn{2}{|c|}{$\begin{array}{c}\text { Proximity } \\
\text { Group }\end{array}$} & \multicolumn{2}{|c|}{ Cronbach's $\alpha$ Coefficient } \\
\hline Viewing Distance & Photo & Pre Education & Post Education \\
\hline Close & $\begin{array}{l}1 \\
2 \\
3\end{array}$ & 0.86 & 0.91 \\
\hline Medium & $\begin{array}{l}4 \\
5 \\
6\end{array}$ & 0.63 & 0.78 \\
\hline Far & $\begin{array}{l}7 \\
8 \\
9\end{array}$ & 0.78 & 0.81 \\
\hline
\end{tabular}


Table 2. Grouping across proximity groups

\begin{tabular}{|c|c|c|}
\hline Random & \multicolumn{2}{|c|}{ Cronbach's $\alpha$ Coefficient } \\
\hline Photo & Pre Education & Post Education \\
\hline $\begin{array}{l}1 \\
4 \\
7\end{array}$ & 0.47 & 0.40 \\
\hline $\begin{array}{l}2 \\
5 \\
8\end{array}$ & 0.39 & 0.48 \\
\hline $\begin{array}{l}3 \\
6 \\
9\end{array}$ & 0.58 & 0.47 \\
\hline
\end{tabular}




\section{Data Analysis}

\section{Impact Analysis}

A two-sample $t$-test, as well as the Wilcoxon ranked sum test were utilized to calculate the amount of change between pre and post intervention responses. The Wilcoxon test is a non-parametric test designed to examine ordinal data sets by ranking the response score medians, rather than calculating response score means. The Wilcoxon test is similar to a $t$-test, but unlike a traditional $t$-test, it assumes that the difference between values may not be consistent. This test is used for comparing nonparametric statistics that are commonly derived from preference scale scores (Purdue, 2010). For example, on a 5-point Likert scale it cannot be assumed that the difference between 1 (highly dissatisfied) and 2 (dissatisfied) is equal to the difference between 2 (dissatisfied) and 3 (neither satisfied nor dissatisfied). The distribution of an individual's preference is not numerically uniform and therefore need to be analyzed with consideration for this assumption.

\section{Proximity Group Analysis}

To establish a deeper understanding of the impacts of educational intervention, the nine photos were divided into three respective groups (close, medium, and far). The mean satisfaction score of each individual participant were calculated for each photo grouping, providing a single score for each proximity group. This calculation was done for pre- and post-intervention satisfaction scores, resulting in six subgroups used to 
further examine the impact of intervention. Figure 6 provides an example of how the score was calculated for each participant. The highlighted numbers in Figure 6 provides an example of one respondent's adjusted scores for the proximity-grouping scheme. The two-sample $t$-test and Wilcoxon rank sum test were run once again using the mean scores.

\begin{tabular}{|c|c|c|c|c|c|c|c|c|}
\hline \multicolumn{9}{|c|}{ Pre-Intervention Satisfaction Scores } \\
\hline \multicolumn{3}{|c|}{ Close } & \multicolumn{3}{|c|}{ Medium } & \multicolumn{3}{|c|}{ Far } \\
\hline Photo 1 & Photo 2 & Photo 3 & Photo 4 & Photo 5 & Photo 6 & Photo 7 & Photo 8 & Photo 9 \\
\hline 3 & 4 & 4 & 5 & 5 & 4 & 4 & 4 & 5 \\
\hline \multicolumn{3}{|c|}{ Mean=3.66 } & \multicolumn{3}{|c|}{ Mean $=4.66$} & \multicolumn{3}{|c|}{ Mean $=4.33$} \\
\hline \multicolumn{9}{|c|}{ Educational Intervention Treatment } \\
\hline \multicolumn{9}{|c|}{ Post-Intervention Satisfaction scores } \\
\hline \multicolumn{3}{|c|}{ Close } & \multicolumn{3}{|c|}{ Medium } & \multicolumn{3}{|c|}{ Far } \\
\hline Photo 1 & Photo 2 & Photo 3 & Photo 4 & Photo 5 & Photo 6 & Photo 7 & Photo 8 & Photo 9 \\
\hline 1 & 2 & 1 & 2 & 3 & 4 & 5 & 5 & 4 \\
\hline \multicolumn{3}{|c|}{ Mean=1.33 } & \multicolumn{3}{|c|}{ Mean $=3$} & \multicolumn{3}{|c|}{ Mean $=4.66$} \\
\hline
\end{tabular}

Figure 6. Single participant mean scores example.

\section{Results}

\section{General Respondent Characteristics}

Of the 151 surveys completed, 97 individuals reported this to be their first safari tour experience, and only eight of the participants had previously visited NCA. In general, there was an even distribution of male $(46 \%)$ and female $(54 \%)$ respondents. The majority (84\%) of the tourists visited from North America or Europe, with 
"pleasure" being the main purpose of travel. The age and level of education for the sample population had an even distribution (Figure 7).
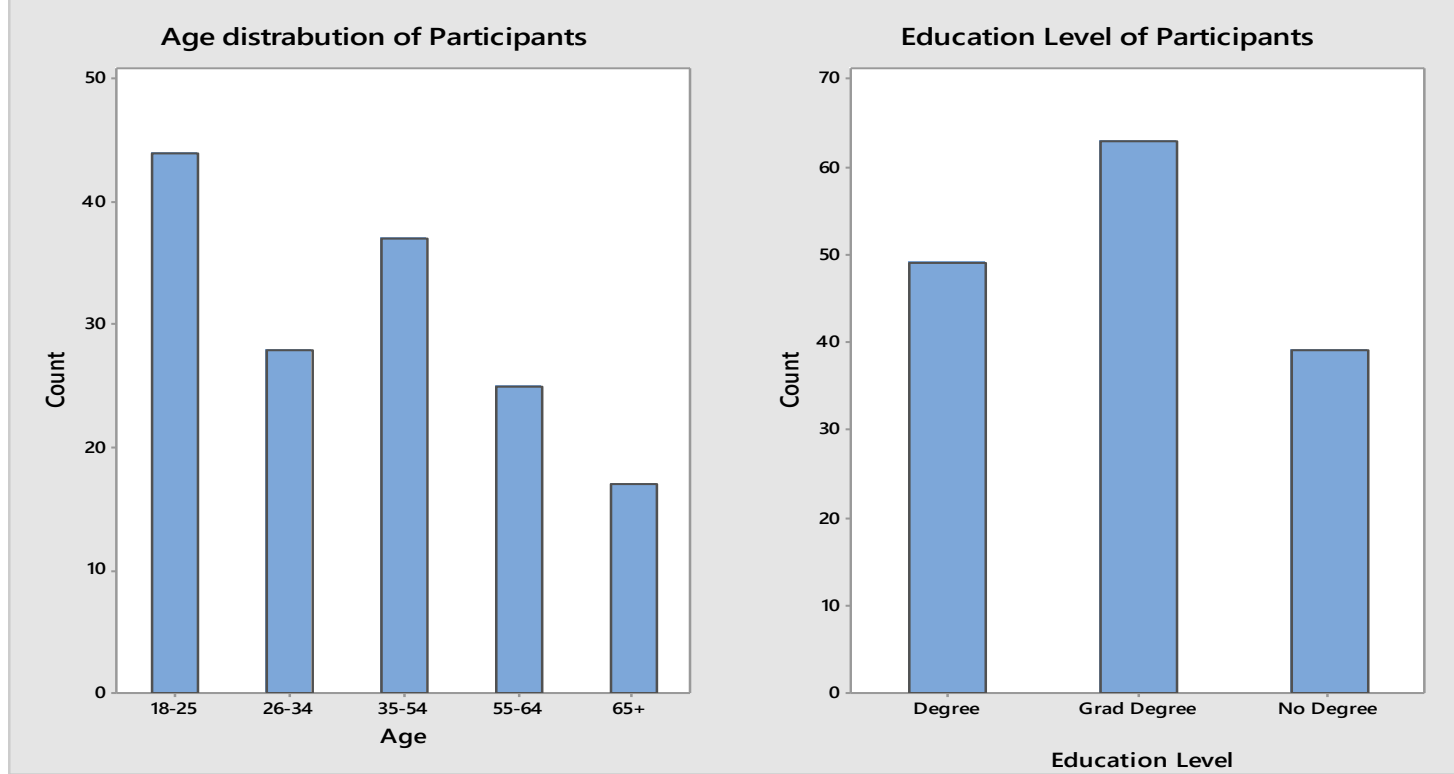

Figure 7. Sample population age and gender.

The majority of participants had completed a college degree (74\%), and nearly $42 \%$ reported having a post-bachelor's degree of some kind. Respondents earned a median income of $\$ 100,000-\$ 149,999(n=34)$. A relatively small number of respondents $(n=16)$ chose not to disclose their income, this however did not disqualify them from the survey due to income being independent from the treatment variable. In Summary, the sample population was predominantly made up of student groups and working professionals that spent personal time and money to visit NCA.

\section{Educational Intervention Impact}

Both ( $t$-test \&Wilcoxon) test were run for each of the nine photos to provide a baseline summary of responses across the entire sample population. The Wilcoxon 
results are presented as median scores for each photo (table 4), whereas the twosample $t$-test provides the mean score for each photo (table 3). The "proximity group" row in tables 3 and 4 provides which viewing distance the photo represented. A twosample $t$-test \& Wilcoxon rank sum test were run once again using the adjusted scores discussed in the data analysis section (Table $3 \& 4$ ). This analysis investigates the impact of educational intervention on each proximity group as a whole.

Note that the $t$-test results (table 3 ) showed the greatest mean difference in responses occurred within the "close" proximity group. Furthermore, the average score was favorable (3.92) prior to intervention and unfavorable (2.59) after intervention. The difference between pre/post scores for the "close" proximity group proved to be significant $(p<0.001)$. The "medium" proximity group showed less of a change in responses than the "close" proximity group. The mean satisfaction score prior to intervention (4.37) was slightly higher than the post intervention score (4.00). Despite a smaller change in average response, this change still proved to be significant $(p=0.001)$. The 'far' proximity group showed the least amount of change $(-0.08)$ when comparing pre/post intervention averages.

Table 4 provides the results from the Wilcoxon rank sum test. Once again, the greatest level of change occurred with responses to images representing close viewing distances, with (photo 2) and (photo 3) showing a change greater than 1. Specifically, the 'close' proximity group score was (4) before educational intervention, compared to a post intervention score of (2.5). The level of change decreases as the viewing distance increased, with the lowest level of change occurring for images representing the 
furthest viewing distances. The level of significance calculated using the Wilcoxon analysis was consistent across all three groups. Note that the amount of change was greater for all three proximity groups when using the Wilcoxon test designed for preference scale data.

When looking at the overall results from both statistical tests there were many identifiable similarities. Both tests showed educational intervention had the greatest impact on satisfaction scores for close wildlife viewing distances. Furthermore, the "close" proximity group was the only group to shift from "satisfied" (4) to "dissatisfied" (2) according to the satisfaction scale. In addition, educational intervention caused a smaller amount of change on satisfaction scores for medium and far groups. 


\begin{tabular}{|c|c|c|c|c|c|c|c|c|c|}
\hline \multirow[b]{2}{*}{$\begin{array}{l}\text { Viewing } \\
\text { Distance }\end{array}$} & \multirow[b]{2}{*}{ Photo } & \multicolumn{4}{|c|}{ Mean scores } & \multicolumn{4}{|c|}{ Group mean } \\
\hline & & $\begin{array}{c}\text { Pre } \\
\text { Education }\end{array}$ & $\begin{array}{c}\text { Post } \\
\text { Education }\end{array}$ & Change & $\begin{array}{l}\text { Significance } \\
\text { ( } P \text { value })\end{array}$ & $\begin{array}{c}\text { Pre } \\
\text { Education }\end{array}$ & $\begin{array}{c}\text { Post } \\
\text { Education }\end{array}$ & Change & $\begin{array}{c}\text { Significance } \\
\text { (P value) }\end{array}$ \\
\hline \multirow{3}{*}{ Close } & 1 & 3.97 & 2.47 & $(-) 1.23$ & $<0.001$ & \multirow{3}{*}{3.92} & \multirow{3}{*}{2.59} & \multirow{3}{*}{ (-) 1.33} & \multirow{3}{*}{$<0.001$} \\
\hline & 2 & 3.77 & 2.40 & $(-) 1.37$ & $<0.001$ & & & & \\
\hline & 3 & 4.04 & 2.62 & $(-) 1.42$ & $<0.001$ & & & & \\
\hline \multirow{3}{*}{ Medium } & 4 & 4.43 & 4.12 & $(-) 0.32$ & $<0.001$ & \multirow{3}{*}{4.37} & \multirow{3}{*}{4.00} & \multirow{3}{*}{ (-) 0.37} & \multirow{3}{*}{$<0.001$} \\
\hline & 5 & 4.33 & 3.85 & $(-) 0.48$ & $<0.001$ & & & & \\
\hline & 6 & 4.36 & 4.03 & $(-) 0.33$ & $<0.001$ & & & & \\
\hline \multirow{2}{*}{ Far } & 7 & 4.01 & 4.20 & 0.19 & 0.066 & \multirow{2}{*}{4.02} & \multirow{2}{*}{4.10} & \multirow{2}{*}{0.08} & \multirow{2}{*}{0.351} \\
\hline & 8 & 3.93 & 3.96 & 0.03 & 0.814 & & & & \\
\hline
\end{tabular}




\begin{tabular}{|l|l|l|l|l|l|l|l|l|l|}
\hline & 9 & 4.13 & 4.16 & 0.03 & 0.749 & & & & \\
\hline
\end{tabular}

Table 3. Two-Sample t-test results

Table 4. Wilcoxon rank sum test results

\begin{tabular}{|c|c|c|c|c|c|c|c|c|c|}
\hline \multirow[b]{2}{*}{$\begin{array}{l}\text { Viewing } \\
\text { Distance }\end{array}$} & \multirow[b]{2}{*}{ Photo } & \multicolumn{4}{|c|}{ Median scores } & \multicolumn{4}{|c|}{ Group median } \\
\hline & & $\begin{array}{c}\text { Pre } \\
\text { Education }\end{array}$ & $\begin{array}{c}\text { Post } \\
\text { Education }\end{array}$ & Change & $\begin{array}{c}\text { Significance } \\
\text { ( } P \text { value) }\end{array}$ & $\begin{array}{c}\text { Pre } \\
\text { Education }\end{array}$ & $\begin{array}{c}\text { Post } \\
\text { Education }\end{array}$ & Change & $\begin{array}{l}\text { Significance } \\
\text { (P value) }\end{array}$ \\
\hline \multirow{3}{*}{ Close } & 1 & 4 & 3 & $(-) 1$ & $<0.001$ & \multirow{3}{*}{4} & \multirow{3}{*}{2.5} & \multirow{3}{*}{ (-) 1.5} & \multirow{3}{*}{$<0.001$} \\
\hline & 2 & 4 & 2.5 & (-) 1.5 & $<0.001$ & & & & \\
\hline & 3 & 4.5 & 2.5 & $(-) 2$ & $<0.001$ & & & & \\
\hline Medium & 4 & 4.5 & 4 & $(-) 0.5$ & $<0.001$ & 4.5 & 4 & (-) 0.5 & $<0.001$ \\
\hline
\end{tabular}




\begin{tabular}{|c|c|c|c|c|c|c|c|c|c|}
\hline & 5 & 4.5 & 4 & $(-) 0.5$ & $<0.001$ & & & & \\
\hline & 6 & 4.5 & 4 & $(-) 0.5$ & $<0.001$ & & & & \\
\hline \multirow{3}{*}{ Far } & 7 & 4 & 4.5 & 0.5 & 0.029 & \multirow{3}{*}{4} & \multirow{3}{*}{4} & \multirow{3}{*}{0} & \multirow{3}{*}{0.085} \\
\hline & 8 & 4 & 4 & 0 & 0.890 & & & & \\
\hline & 9 & 4 & 4 & 0 & 0.668 & & & & \\
\hline
\end{tabular}




\section{Conclusion}

The findings of this case study show that the educational intervention had the greatest impact on tourists' preference to achieve close proximities to wildlife. The key aspect of these findings show that tourists not only reported lower satisfaction with viewing lions at close distances but also greater satisfaction with viewing lions from ecologically responsible distances. In other words, the tourists were receptive to the educational intervention and viewed it as a positive addition to their safari experience, rather than a burden that lowered the overall quality of experience. These baseline results suggest that educating the visitor is a viable management strategy for sustaining both the quality of experience for the tourists' while protecting the ecological integrity of the conservation area. Specifically, this study suggests that perceived satisfaction with viewing a flagship species at close proximities can be altered by providing a tourist with interpretive educational information.

Tanzania continues to promote safari tourism as vital contributor to the current and projected GDP (Cunningham et al., 2015). As safari-related tourism continues to be the foundation of Tanzania's tourism sector, the natural resources that drive visitation must be continually monitored through a comprehensive management plan. As crowding adversely influences a tenuous ecological balance, human dimensions of wildlife management become more critical. The need for a management approach that recognizes the interconnectedness of the economy, culture, and environment of a destination, is supported by research that addresses the complexity of non-consumptive wildlife viewing to inform responsible policies and practices. If the natural environment 
is degraded through crowding, the value of experience may also decline potentially resulting in less revenue, less opportunity for employment and eventually a decline of the industry as a whole.

\section{Recommendations}

Future research on the development and implementation of an educational intervention strategy is warranted. First, it would be worth looking into how much the measured change in perceptions correlates to actual behavior. In other words, was this a case of responder bias where the tourists simply state that they wanted to take part in environmentally responsible behavior to satisfy the survey or are the responses consistent with the actual behavior of the tourists? Additionally, it would be worthwhile to test for variability with a post-experience survey. Furthermore, delivering the survey instrument at various times of the year would measure if seasonality and an influx in visitation altered the perceptions of tourists in regards to wildlife viewing distances. Finally, administering this survey methodology at other wildlife tourism destinations that struggle with issues of overcrowding would indicate the transferability of this type of educational intervention as management strategy. 


\section{References}

Ballantyne, R., Packer, J., Hughes, K. and Dierking, L. (2007). Conservation learning in wildlife tourism settings: lessons from research in zoos and aquariums. Environmental Education Research, 13(3), 367-383.

Bland, J. M., \& Altman, D. G. (1997). Statistics notes: Cronbach's alpha.Bmj, 314(7080), 572.

Brand, U., Görg, C., Hirsch, J., \& Wissen, M. (2008). Conflicts in environmental regulation and the internationalization of the state: contested terrains. New York: Routledge.

Cable, T. T., Knudson, D. M., \& Stewart, D. J. (1984). The economic benefits to visitors of an interpretive facility. The Journal of Environmental Education, 15(4), 32-37.

Cunningham, Victoria; Haji, Mahjabeen; Morisset, Jacques. (2015). Tanzania economic update: the elephant in the room - unlocking the potential of the tourism industry for Tanzanians. Tanzania economic update; issue no. 6. Washington, DC: World Bank Group. http://documents.worldbank.org/curated/en/716911468305677763/Tanzaniaeconomic-update-the-elephant-in-the-room-unlocking-the-potential-of-the-tourismindustry-for-Tanzanians

Daniel, T. C. (2001). Whither scenic beauty? Visual landscape quality assessment in the 21st century. Landscape and urban planning, 54(1), 267-281.

Durant, S. M., Craft, M. E., Hilborn, R., Bashir, S., Hando, J., \& Thomas, L. (2011). Long-term trends in carnivore abundance using distance sampling in Serengeti National Park, Tanzania. Journal of Applied Ecology, 48(6), 1490-1500.

Falk, J. H., Ballantyne, R., Packer, J., \& Benckendorff, P. (2012). Travel and learning: A neglected tourism research area. Annals of Tourism Research, 39(2), 908-927.

Fryxell, J. M., Mosser, A., Sinclair, A. R., \& Packer, C. (2007). Group formation stabilizes predator-prey dynamics. Nature, 449(7165), 1041-1043.

Garland, E. (2008). The elephant in the room: confronting the colonial character of wildlife conservation in Africa. African Studies Review, 51(03), 51-74.

Garrote, G., De Ayala, R. P., Pereira, P., Robles, F., Guzman, N., García, F. J., \& Barroso, J. L. (2011). Estimation of the Iberian lynx (Lynx pardinus) population in the Doñana area, SW Spain, using capture-recapture analysis of camera-trapping data. European Journal of Wildlife Research, 57(2), 355-362.

Gimblett, R., Daniel, T., \& Meitner, M. J. (2000). An individual-based modeling approach to simulating recreation use in wilderness settings. In: Cole, David N.; McCool, Stephen F.; Borrie, William T.; O'Loughlin, Jennifer, comps. 2000. Wilderness science in a time of change conference-Volume 4: Wilderness visitors, experiences, and visitor management; 1999 May 23-27; Missoula, MT. Proceedings RMRS-P-15-VOL-4. Ogden, UT: U.S. Department of Agriculture, Forest Service, Rocky Mountain Research Station. p. 
99-106

Gössling, S., Hall, C. M., \& Weaver, D. (Eds.). (2009). Sustainable tourism futures: Perspectives on systems, restructuring and innovations. Routledge.

Habron, D. (1998). Visual perception of wild land in Scotland. Landscape and urban Planning, 42(1), 45-56.

Hawkins, D. E., Ruddy, J., \& Ardah, A. (2012). Reforming Higher Education: The Case of Jordan's Hospitality and Tourism Sector. Journal of Teaching in Travel \& Tourism, 12(1), 105-117.

Higginbottom, K., Green, R., \& Northrope, C. (2003). A framework for managing the negative impacts of wildlife tourism on wildlife. Human Dimensions of Wildlife, 8(1), 1-24.

Hopcraft, J. G. C., Sinclair, A. R. E., \& Packer, C. (2005). Planning for success: Serengeti lions seek prey accessibility rather than abundance. Journal of Animal Ecology, 74(3), 559-566.

Kroh, D. P., \& Gimblett, R. H. (1992). Comparing live experience with pictures in articulating landscape preference. Landscape Research, 17(2), 58-69.

Melita, A. W., \& Mendlinger, S. (2013). The Impact of Tourism Revenue on the Local Communities' Livelihood: A Case Study of Ngorongoro Conservation Area, Tanzania. Journal of Service Science and Management, 6(1), 117.

Moscardo, G., Woods, B., \& Greenwood, T. (2001). Understanding visitor perspectives on wildlife tourism. Gold Coast: CRC for Sustainable Tourism.

Mosser, A., \& Packer, C. (2009). Group territoriality and the benefits of sociality in the African lion, Panthera leo. Animal Behavior, 78(2), 359-370.

Ngorongoro Conservation Area (NCA). (2016). In Encyclopædia Britannica. Retrieved fromhttps://www.britannica.com/place/Ngorongoro-Conservation-Area

Nyahongo, J., Lowassa, A., Malugu, L., Nkya, H., Mwakalebe, G., Thomassen, J., \& Stokke, S. (2007). The effects of vehicle congestion on the environment-an EIA in the Ngorongoro crater. NINA Rapport 258: 83 pp., 258.

Palmer, J. F., \& Hoffman, R. E. (2001). Rating reliability and representation validity in scenic landscape assessments. Landscape and urban planning,54(1), 149-161.

Palmer, A. R., \& Hoffman, M. T. (1997). Nama-karoo. Vegetation of Southern Africa, 167, 186.

Panitchpakdi, K. (2012). Analyzing sustainability of a local community by EBS theory: The case of Kao Yi Sarn, Samut Songkram, Thailand. Journal of ASIAN Behavioural Studies, 2(4).

Powell, R. B., Kellert, S. R., \& Ham, S. H. (2009). Interactional theory and the sustainable naturebased tourism experience. Society and Natural Resources, 22(8), 761-776. 
Semeniuk, C. A., Haider, W., Beardmore, B., \& Rothley, K. D. (2009). A multi-attribute trade-off approach for advancing the management of marine wildlife tourism: a quantitative assessment of heterogeneous visitor preferences. Aquatic Conservation: Marine and Freshwater Ecosystems, 19(2), 194.

Skinner, A. R., Hay, R. L., Masao, F., \& Blackwell, B. A. B. (2003). Dating the Naisiusiu Beds, Olduvai Gorge, by electron spin resonance. Quaternary Science Reviews, 22(10), 13611366.

Tavakol, M., \& Dennick, R. (2011). Making sense of Cronbach's alpha.International journal of medical education, 2, 53.

United Nations World Tourism Organization (UNWTO). (2006) UNWTO's Declaration on Tourism and the Millennium Goals: Harnessing Tourism for the Millennium Development Goals; UNWTO: Madrid, Spain.

Van den Berg, A. E., Koole, S. L., \& van der Wulp, N. Y. (2003). Environmental preference and restoration:(How) are they related?. Journal of environmental psychology, 23(2), 135146.

Williams, P. H., Burgess, N. D., \& Rahbek, C. (2000). Flagship species, ecological complementarity and conserving the diversity of mammals and birds in sub-Saharan Africa. Animal Conservation, 3(3), 249-260.

World Tourism \& Travel Council (WTTC). (2015). Travel \& Tourism: Economic Impact 2015, Tanzania; WTTC: London, UK. 